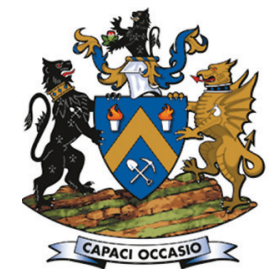

Affiliation:

1 Department of Mining Engineering, University of Pretoria.

Correspondence to: D.F. Malan

Email:

francois.malan@up.ac.za

Dates:

Received: 1 Dec. 2020

Revised: 19 Mar. 2021

Accepted: 19 Mar. 2021

Published: May 2021

\section{How to cite:}

Malan, D.F. and Napier, J.A.L. 2021

A review of the role of underground measurements in the historical development of rock engineering in South Africa. Journal of the Southern African Institute of Mining and Metallurgy, vol. 121, no. 5, pp. 201-216.

DOI ID:

http://dx.doi.org/10.17159/24119717/1443/2021

ORCID

D.F. Malan

https://orchid.org/0000-00029861-8735

\title{
A review of the role of underground measurements in the historical development of rock engineering in South Africa
}

\author{
D.F. Malan ${ }^{1}$ and J.A.L. Napier ${ }^{1}$
}

\begin{abstract}
Synopsis
This paper describes some important aspects associated with historical underground measurements in South African gold and coal mines. Deformation measurements were used to confirm the use of elastic theory to simulate the rock mass behaviour in the Witwatersrand gold mines in the 1960s. Although a prominent time-dependent component of stope closure was measured as early as the 1930s, it was ignored owing to the benefit of adopting elastic theory. Neglecting the time-dependent response of the rock for many decades resulted in important aspects such as the effect of mining rate, the effect of advance per blast, and the need for enhanced design criteria not being explored. Recent work is only now starting to address this gap in knowledge. In-situ measurements of large coal specimens in the 1960s and 1970s indicated that a linear formula may possibly be a better approximation of coal pillar strengths. This alternative formulation was never adopted, however, as the power law strength formula was already deeply entrenched in the industry at that stage. In spite of these apparent failures to continuously generate and adopt new knowledge, a key lesson learnt is that major advances in rock mechanics will not be possible without careful monitoring of the rock mass behaviour in experimental sites. Areas requiring further research, such as pillar strength formulae for the Bushveld Complex and enhanced design criteria for the gold mines, can only be developed using extensive underground monitoring programmes.
\end{abstract}

\section{Keywords}

rock engineering, underground monitoring, elastic theory, time-dependence, pillar strength.

\section{Introduction}

Even after many decades of research, a number of key rock mechanics questions remain unanswered. Jooste and Malan (2020) recently highlighted the need for additional research in the area of layout design criteria for deep gold mines. Two popular design criteria are currently used in the deep gold mines of South Africa, namely average pillar stress (APS) and energy release rate (ERR). The introduction of these criteria assisted greatly in reducing areas of high stress concentrations, but both criteria are of limited use. It is, for example, not clear what the maximum value of APS on remnants and pillars should be for safe extraction, and it is questionable whether numerical modelling programs calculate this parameter correctly in areas where inelastic rock behaviour is prominent. Elastic ERR has a significant drawback as no dissipative mechanisms are incorporated to allow for failure of the rock mass. Improved methods to estimate the risk when mining pillars and remnants in the deep gold mines are therefore urgently required.

As a second example, the difficulties in estimating the strength of pillars in bord and pillar layouts in the Bushveld Complex are well known (Malan and Napier, 2011). Empirical power-law strength formulae nevertheless remain popular and this is the standard method to determine pillar strength in the hard rock South African platinum and chrome mining industry. The typical form of the formula is well known:

$$
\sigma_{s}=K \frac{w^{\alpha}}{h^{\beta}}
$$

In industry, it is commonly accepted that $K$ reflects the fitted 'strength' of the in-situ rock, $w$ is the width of the (square) pillar, $h$ is the height in metres, and $\alpha$ and $\beta$ are dimensionless constants. Bieniawski and van Heerden (1975) made the interesting comment that $K$ given in Equation [1] has the dimensions of $\left(\mathrm{MPa} \cdot \mathrm{m}^{\alpha-\beta}\right)$. Only if $\alpha=\beta$ does $K$ have the meaning of the strength of a cube of rock with unit side length. This subtlety is ignored in industry and it is simply assigned the units of MPa.

The parameters $\alpha$ and $\beta$ are equal to 0.46 and 0.66 respectively in the well-known Salamon and Munro (1967) coal pillar strength formula. For the Hedley and Grant (1972) formula used in the 


\section{A review of the role of underground measurements in the historical development}

Bushveld Complex, $\alpha=0.5$ and $\beta=0.75$. The $K$-value is typically taken as between a third and two thirds of the laboratory UCS strength of the rock. A significant effort to develop a new pillar strength formula for the Bushveld Complex was undertaken by the PlatMine research programme (Ryder, Watson, and Kataka, 2005). From this study, it was proposed that $K=67 \mathrm{MPa}, \alpha=$ 0.67 , and $\beta=0.32$. A new strength formula was also derived for the Merensky Reef pillars (Watson et al., 2008). For the Merensky formula, $K=86 \mathrm{MPa}, \alpha=0.76$, and $\beta=0.36$.

For the new UG2 and Merensky pillar strength formulae, note that $\alpha>\beta$. This is in contrast to the Hedley and Grant and Salamon and Munro formulae where $\alpha<\beta$. The implications of this can be examined by writing Equation [1] in its alternative form. As pillar volume is given by $V=w^{2} h$ and defining the width to height ratio, $R=w / h$, Equation [1] can be expressed as:

$$
\sigma_{S}=K V^{(\alpha-\beta) / 3} R^{(\alpha+2 \beta) / 3}
$$

It can be seen from Equation [2] that if $\alpha=\beta$, the pillar strength is independent of the pillar volume whereas if $\alpha>\beta$, as in the Salamon and Munro and Hedley and Grant formulations, the pillar strength is predicted to decrease as the pillar volume is increased even if the pillar shape is unchanged. The pillar strength for the Merensky and UG2 formulations, $\alpha>\beta$, will increase as the pillar volume is increased. This is illustrated in Figure 1. It is not clear whether the increase in pillar strength for an increase in volume predicted by the Merensky formula is an appropriate representation of underground pillar strength. Note that the results in the graph are for a cube with a constant width to height ratio $(R=1)$ where only the volume of the cube is increased. It is expected intuitively that as the volume of rock increases, more discontinuities may be present that may weaken the volume of rock. Bieniawski and van Heerden (1975) emphasised the need for in-situ large-scale tests (Figure 2). They stated that for the small laboratory specimens, fewer discontinuities are present and therefore small specimens are stronger than larger specimens.

An objection raised by Bieniawski (1992) is that, according to the Salamon and Munro power law formulation, the cube strength $(w=h, \mathrm{R}=1$ ) would continue to decrease indefinitely with side length. This is considered unreasonable (Hustrulid, 1976). Most laboratory and field data indicates that the $w: h$ strengthening curve has a zero or positively upwards curvature

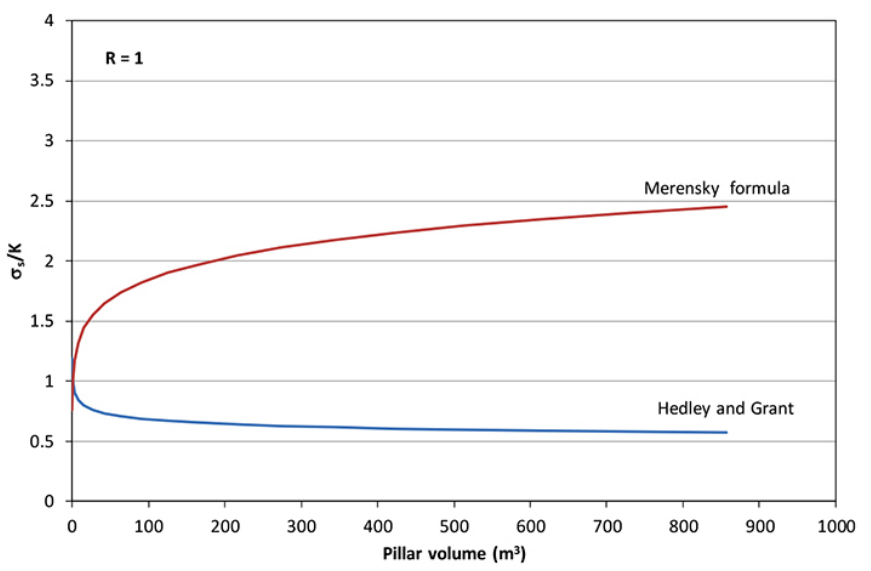

Figure 1-Effect of pillar volume on pillar strength for a constant width to height ratio of 1 (for a cube)
(Ryder and Jager, 2002). The power law formula with $\beta>\alpha$ predicts downward curvature, in contrast. An alternative 'linear' equation, with no volumetric size effect, was therefore proposed and it directly expresses the strengthening effect of the $w: h$ ratio (Bieniawski, 1992).

$$
\sigma_{s}=K\left(A+B \frac{w}{h}\right)
$$

where $K(\mathrm{MPa})$ is the 'in-situ' strength of a large block $(w: h=1)$ of pillar material and $A$ and $B$ are dimensionless strengthening parameters such that $\mathrm{A}+\mathrm{B}=1$.

It is of interest to note that the original form of the SalamonMunro pillar strength formulation (Equation [1]) is quoted in the later paper by Salamon, Ozbay, and Madden (1998) in the form

$$
\sigma_{P w r}=K\left(\frac{W}{W_{0}}\right)^{\alpha}\left(\frac{M}{M_{0}}\right)^{\beta},
$$

where it is stated that 'the multiplier $K$ is the compressive strength of a reference block of coal of height $M_{0}$ and width $W_{0}$ '. Equation [4] is a more satisfactory formulation of the power law relationship but does not include any physical insights into the controlling mechanisms of failure in the pillar system. There would seem to be considerable merit in investigating a non-dimensional strength formula which would include a fundamental length scale that can be related, for example, to a characteristic joint spacing as well as the inclusion of some measure of the fundamental strength of the intact pillar material.

It is clear from these examples that additional research is required regarding the behaviour of the rock mass in the Witwatersrand and Bushveld Complex mines. Owing to the difficulty of many of these investigations, many modern studies are office-based, typically using computer simulations, with little or no comparison to underground observations or measurements. The objective of this paper is to review some historical in-situ measurements at experimental sites and to highlight how these had a profound effect on the development of rock engineering in South Africa. The intention is to stimulate renewed interest in the value of these in-situ measurements and illustrate the urgent need for more experimental data. Of particular interest are the

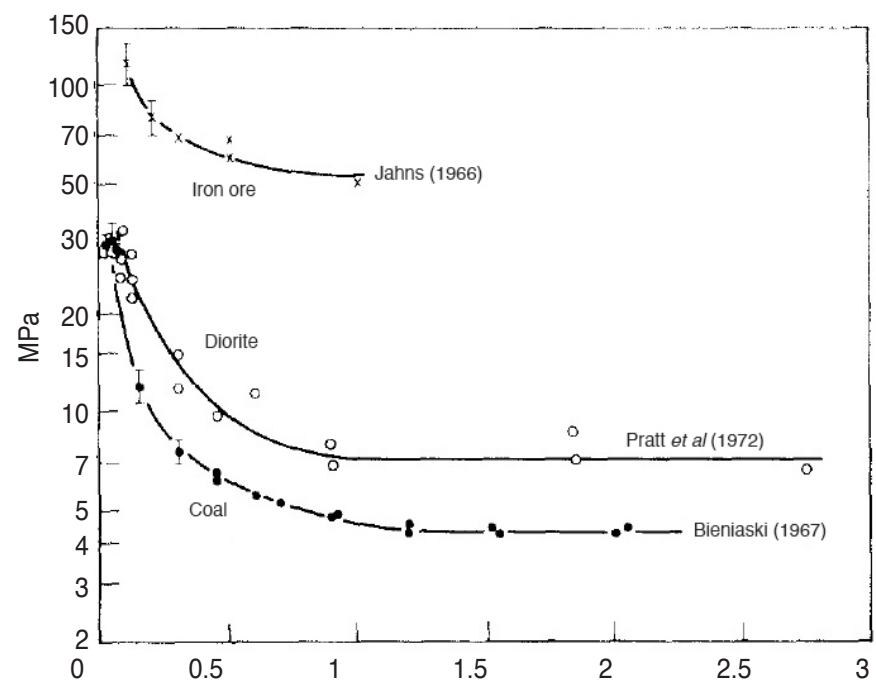

Figure 2-Bieniawski and van Heerden (1975) emphasised that rock strength asymptotically approaches a constant value when conducting large-scale testing 


\section{A review of the role of underground measurements in the historical development}

valuable convergence measurements taken before the 1960 s and how these revealed an 'inconvenient truth' that was ignored with the widespread adoption of elastic theory. As seismic data and ejection velocities for rockburst support design in the South African mines are extensively described in a number of papers (e.g. see Durrheim, 2010; Malan and Napier, 2018), this topic is excluded from this study, as are laboratory tests on small-scale samples.

Franklin (1975) emphasised the role of monitoring in rock engineering. He stated that 'One solution for design based on uncertain data is to adopt a conservative approach with correspondingly high factors of safety. A better alternative is to recognize that much of the design work must be done in the course of execution of the project based on observations of actual rock conditions and on the records obtained by monitoring.' This is particularly relevant to the pillar strength problem in South Africa as it is suspected that the methodology of using a Hedley and Grant formulation, with a substantially downgraded value of $K$, leads to a conservative approach. As the depth increases in these mines, carefully designed experimental work and monitoring will be required to develop more appropriate strength formulae. Szwedzicki (1989) refers to 'geotechnical assessment deficiencies', which is the difference between prediction and the actual performance of the rock mass. This may lead to collapses and other rock engineering disasters. To minimize these potential problems, site characterization and geotechnical analysis should be carefully planned to understand how the various parameters control the behaviour of the rock mass.

The following sections illustrate the interesting history of stope deformation monitoring and how the adoption of elastic theory eventually leads to geotechnical assessment deficiencies.

\section{Early deformation measurements}

Some of the earliest references to closure measurements in South

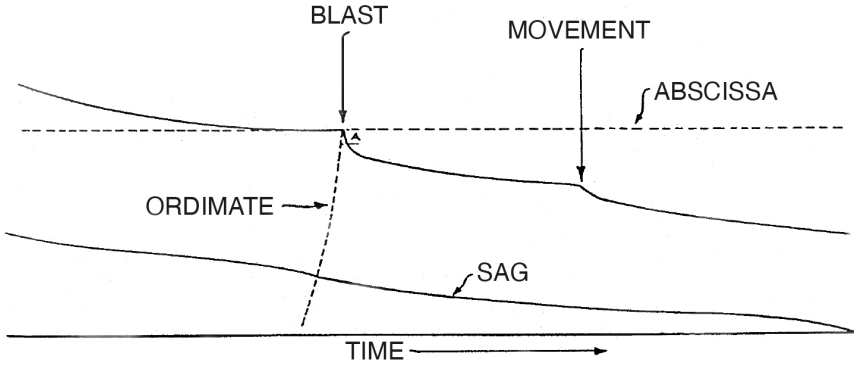

Figure 3-Continuous closure measurements recorded at Crown Mines (after Mickel, 1935). Note that the closure increases downwards on the vertical axis

African gold mines can be found in papers by Altson (1933) and Mickel (1935). A report on closure measurements (termed 'hangingwall sag') by R.K. Bradley was published as part of the discussion of the paper by Mickel. Some of his continuous closure profiles are depicted in Figure 3. The detail of his closure measuring instrument is shown in Malan, Napier, and Janse van Rensburg (2007). It is interesting to note that the prominent time-dependent closure between blasts was already recorded in 1935.

The National Mechanical Engineering Research Institute of the CSIR conducted deformation measurements at Harmony Gold Mine from 1955 to 1957 (Barcza and von Willich, 1958; CSIR, 1958). Measurements were taken in the ventilation shaft, in two haulages, and closure measurements were taken in stopes. Figure 4 illustrates the layout indicating that early mining of the ventilation shaft pillar occurred, which is why measurements in this shaft were of particular interest. For the period during which the area around the ventilation shaft could be considered as 2D (1957), attempts were made to find a relationship between maximum closure and stope span. This is shown in Figure 5. In

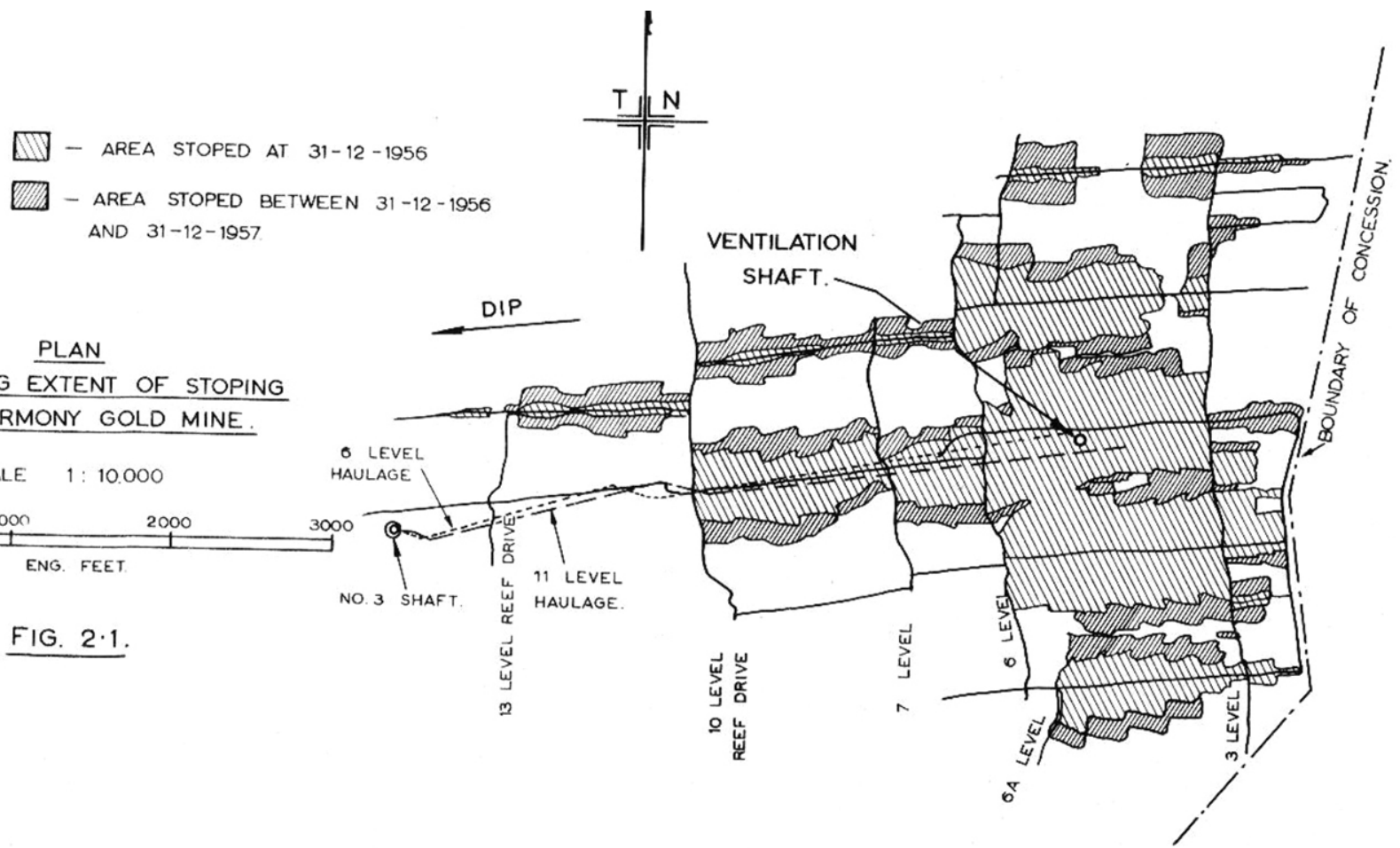




\section{A review of the role of underground measurements in the historical development}

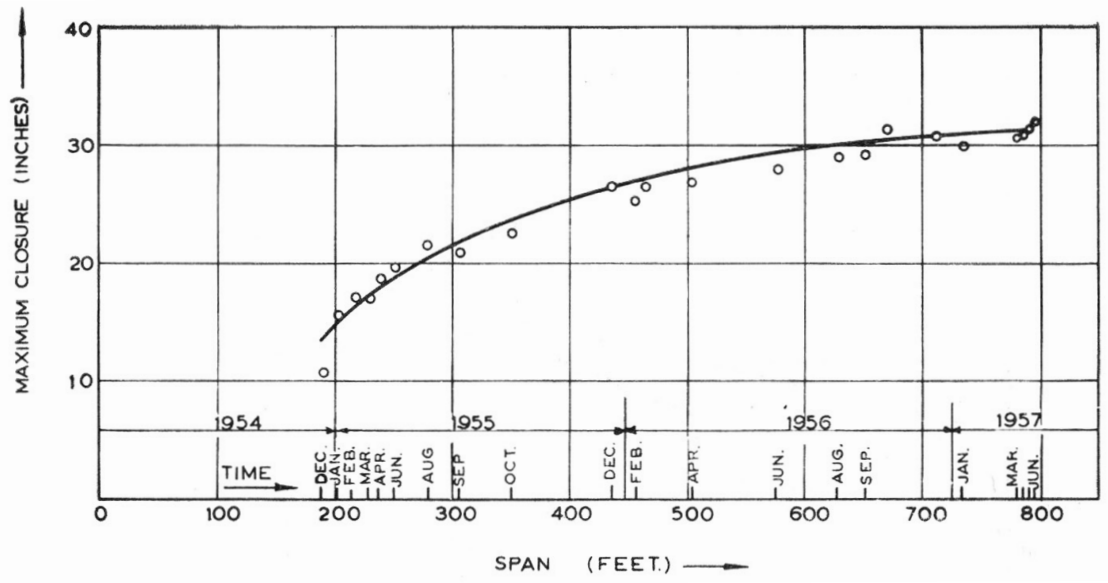

Figure 5-Relationship between maximum closure and stope span at Harmony Gold Mine (Barcza and von Willich, 1958)

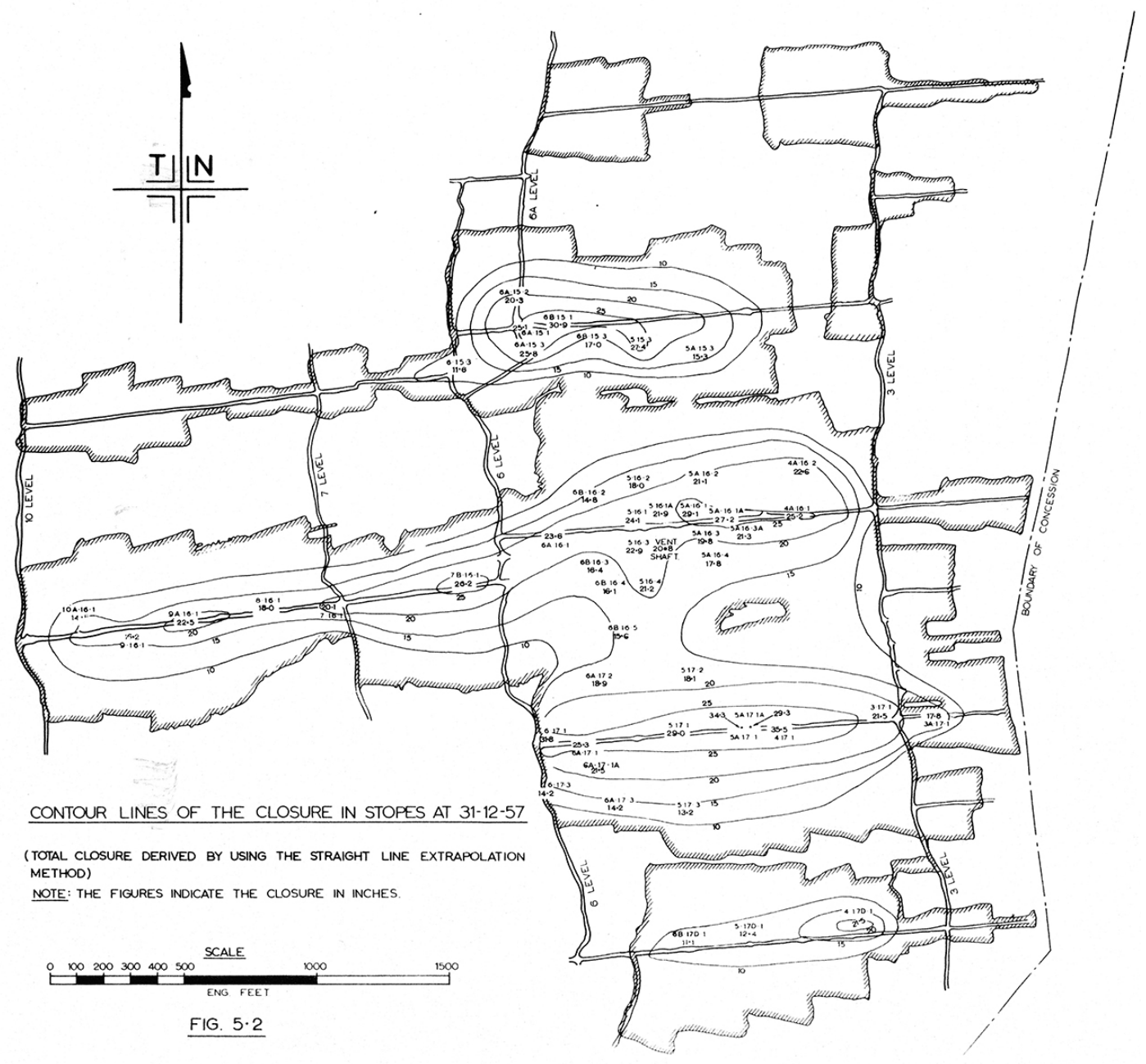

Figure 6-Contour lines of closure in the stope at Harmony Gold Mine during December 1957 (after CSIR, 1958)

1958, the geometry became more complex and as elastic analysis methods for complex layout geometries were not yet available, the CSIR report mentioned that 'In view of the fact that the excavation is of a more irregular shape during the year under review, it was not possible to relate the extent of movement to any variable factor such as stoping span.' The results nevertheless indicated that the zone of movement and fracturing around the ventilation shaft became progressively larger as the excavated area increased in size. An important finding was that points above a stoping excavation move downwards while points below the excavation move upwards. This was important evidence for the adoption of elastic theory to simulate the behaviour of the intact rock mass in the 1960s. Interestingly, the CSIR noted in the report that from the measurements they could deduce that closure on the reef elevation was composed of approximately $60 \%$ hangingwall movement ('sag') and $40 \%$ footwall rise. Estimated contours of closure lines were derived from the measurement points. These are given in Figure 6, and this is noteworthy as it probably was the first contour plot of closure in a gold mine stope. 


\section{A review of the role of underground measurements in the historical development}

Leeman (1958) conducted extensive measurements of closure and ride in the 64E stope, Angelo Section, at East Rand Proprietary Mines (ERPM). The depth below surface was approximately $2700 \mathrm{~m}$. These experiments were conducted to investigate if there was a relationship between closure behaviour and rockbursts. The mine layout in those years and the experimental site are shown in Figure 7 . The instruments used were a 'plumb-bob' closure and ride meter and the CSIR closure
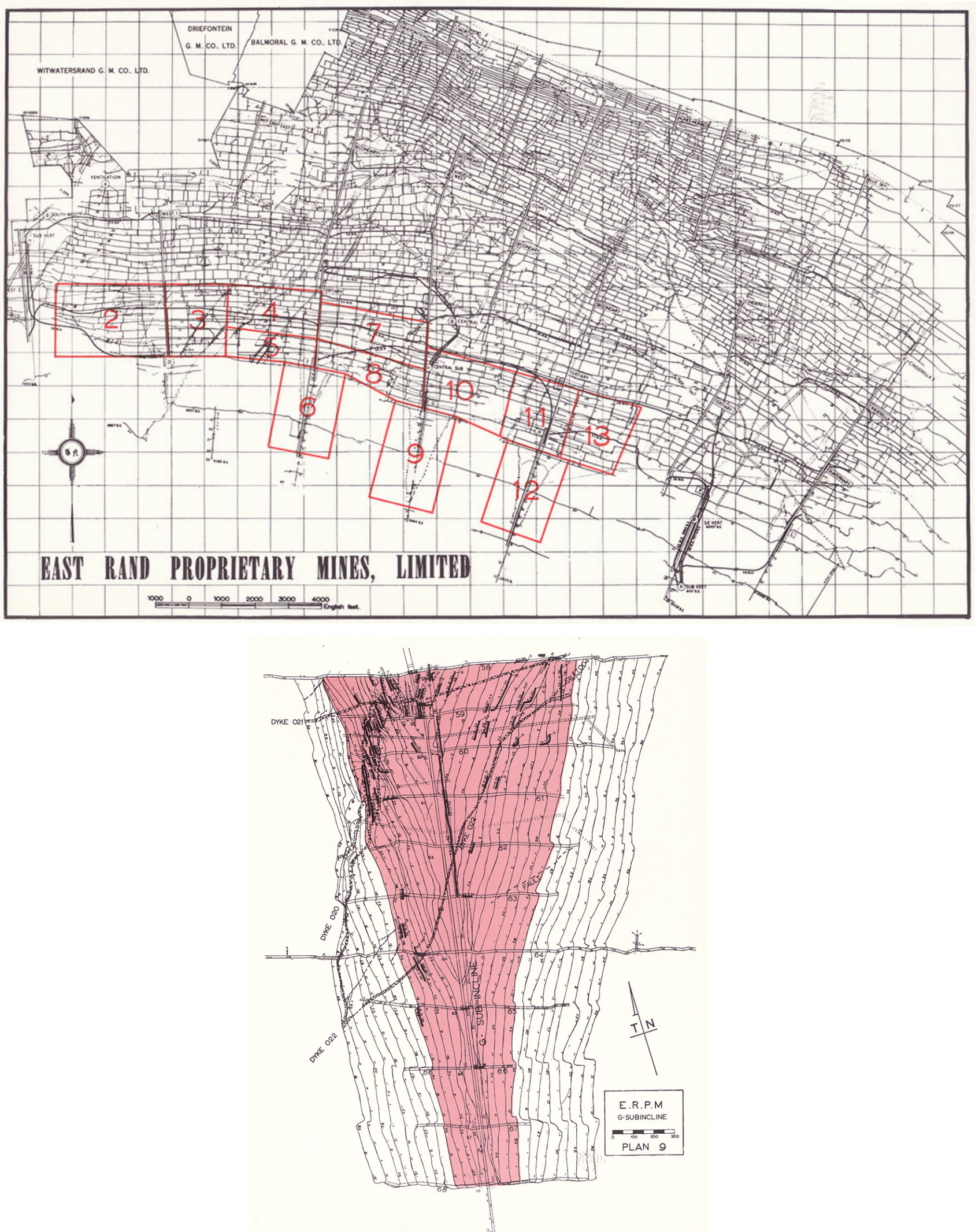

Figure 7-Locality of the longwall stope at ERPM where continuous closure measurements were recorded (area 9) (after Leeman, 1958). The longwall is shown at the bottom 


\section{A review of the role of underground measurements in the historical development}

recorder. These instruments are shown in Figure 8. Characteristic data from the closure recorders is given in Figure 9. Leeman emphasised the ongoing closure, even in the absence in blasting, and referred to this as 'gradual closure'.

Leeman found that the closure decreased as the measurement position moved away from the face (Figure 10). This figure
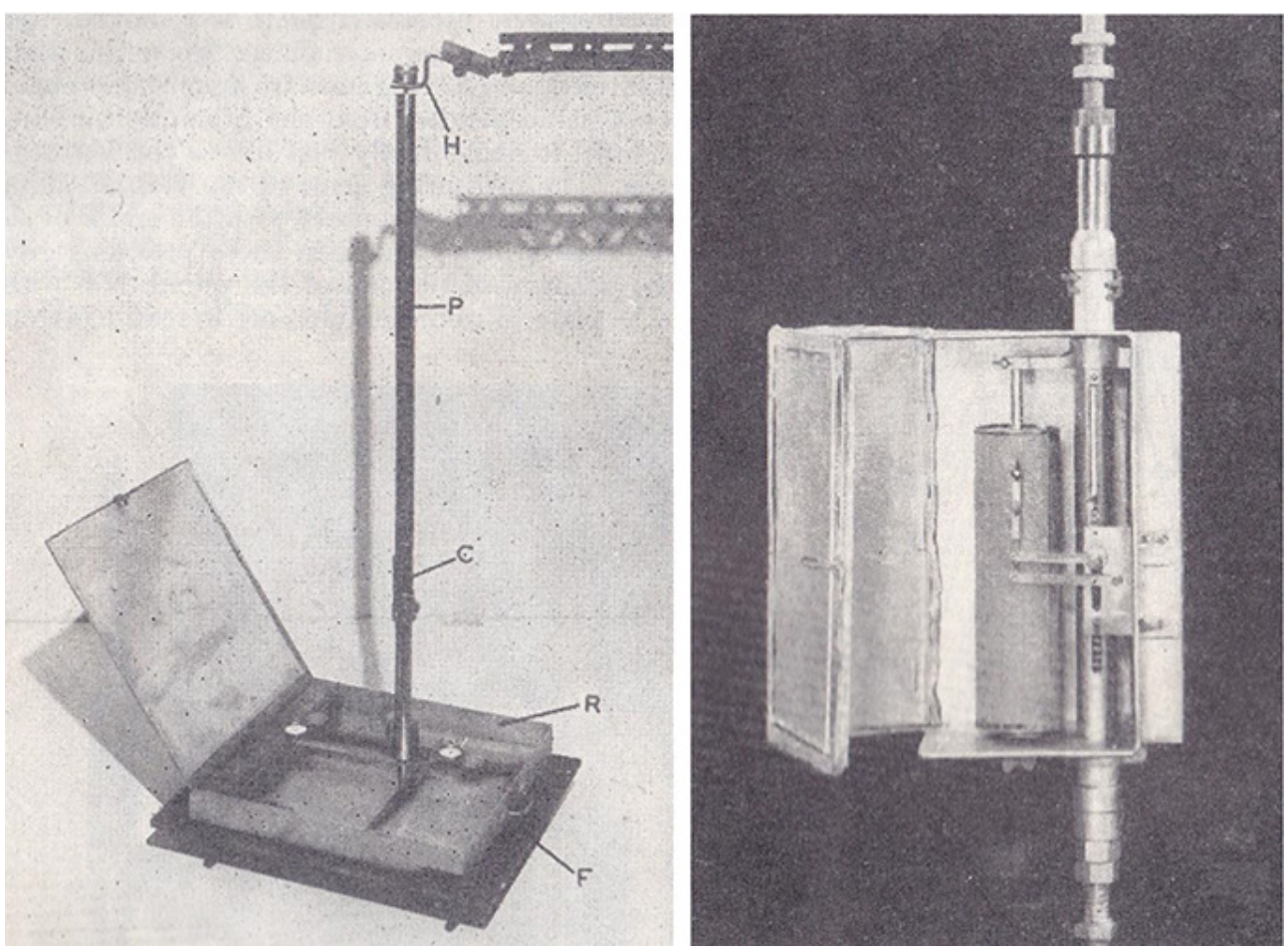

Figure 8-Type of closure instruments used. A plumb-bob closure and ride meter is shown on the left and a CSIR closure recorder on the right (after Leeman, 1958)

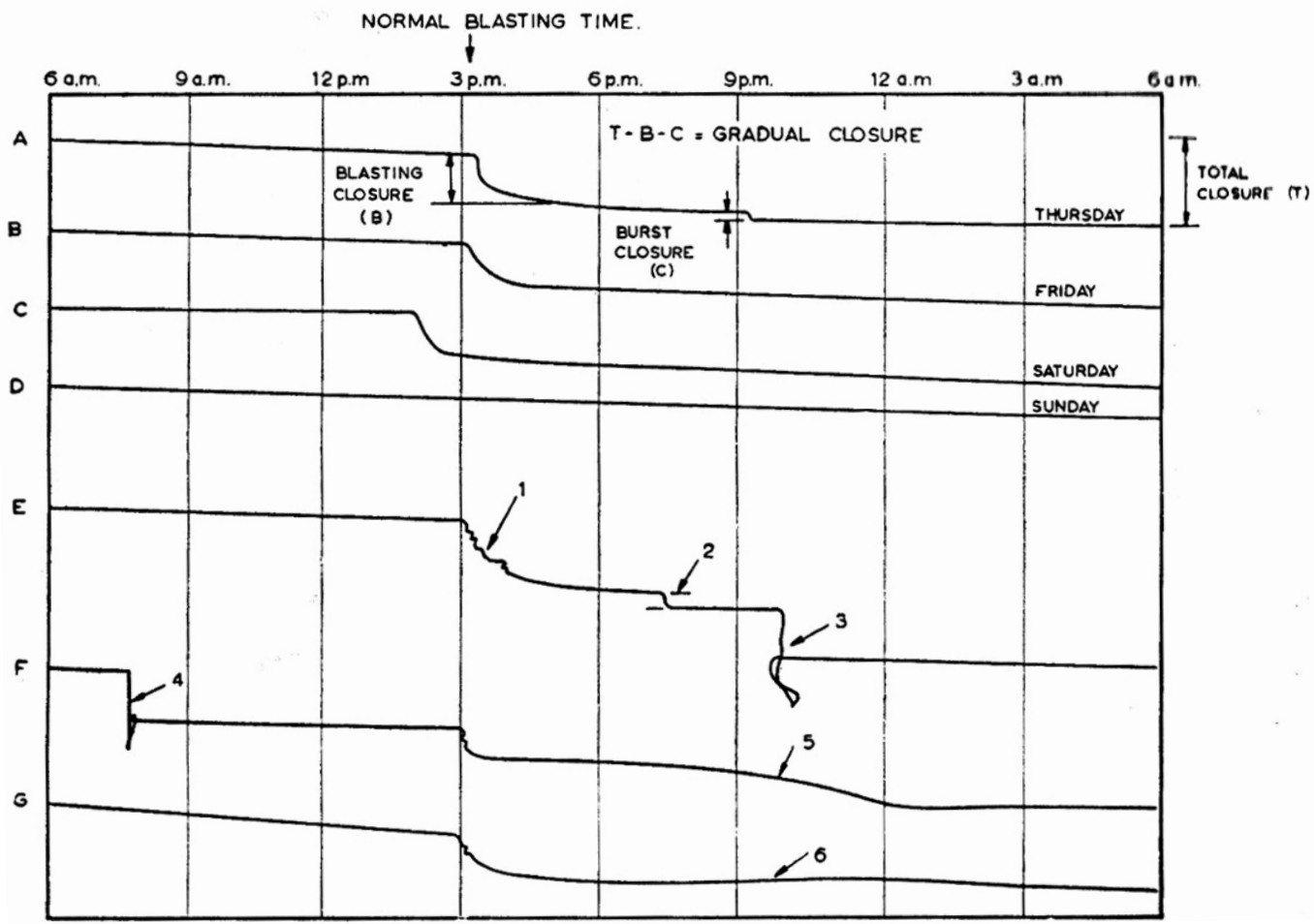

Figure 9-Characteristic closure curves recorded by the continuous closure recorders. Note the ongoing 'gradual closure' during Sunday, when no blasting occurred (after Leeman, 1958) 


\section{A review of the role of underground measurements in the historical development}

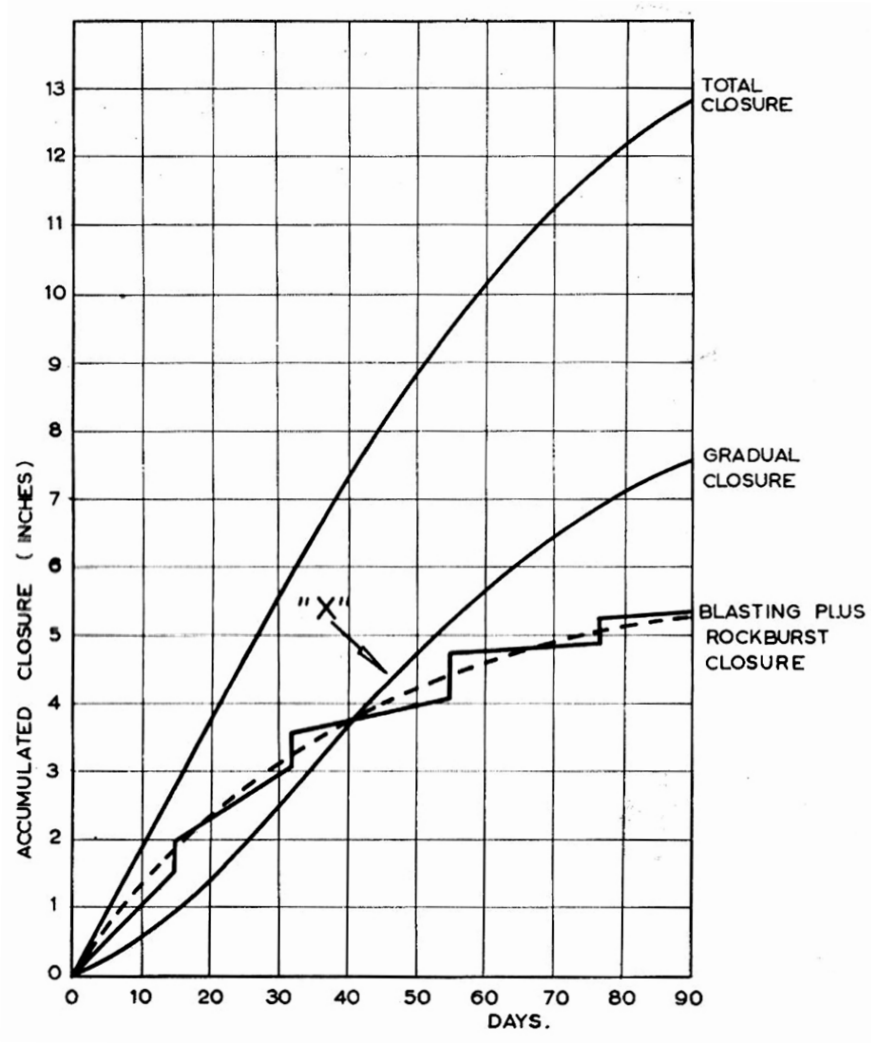

Figure 10-Characteristic closure curves recorded in the stope as the measurement point moved further away from the face into the back area (after Leeman, 1958)

between closure behaviour and rockbursts. The rate of gradual closure was a minimum on Sundays when no blasting occurred and he concluded 'the effect of blasting is to accelerate the gradual closure in a stope.'

It is significant that the Leeman (1958) paper illustrated very clearly that the fractured rock mass surrounding the stopes results in time-dependent closure behaviour when measuring in a continuous fashion between the footwall and hangingwall of the stope. Evidence of the fractured rock mass, consisting of a hard brittle material, behaving in a creep-like fashion was a major discovery. Creep behaviour is more usually associated with soft rocks such as salt and potash. Surprisingly, this important finding was ignored after 1958 and the Leeman paper gathered dust for the next three decades.

Systematic continuous closure measurements and the timedependent nature of the rock mass were only recorded again in the 1990s as described by Malan, Napier, and Janse van Rensburg (2007). The reason for this was probably that elastic theory was already deeply entrenched by the 1960s, as described in the next section.

\section{Deformation measurements and elastic theory}

Hoek (2006) wrote that 'Much of the early work in rock mechanics applied to mining was focused on the problem of rockbursts and this work is dominated by theoretical solutions which assume isotropic elastic rock and which make no provision for the role of structural discontinuities. In the first edition of Jaeger and Cook's book, Fundamentals of Rock Mechanics (1969), mention of structural discontinuities occurs on about a dozen of the 500 pages of the book. This comment does not imply criticism of this outstanding book but it illustrates the dominance of elastic theory in the approach to rock mechanics associated with deep-level mining problems.' It seems as if the adoption of elastic theory to describe the behaviour of the rock mass had already gained momentum in the 1950s. Roux and Denkhaus (1954) describe the approach of assuming an elastic, homogeneous, and isotropic rock mass to predict the distribution and magnitude of stress around mining excavations. In the paper, they gave solutions for the stress distribution around circular and elliptical openings. For more complex mining geometries, such as the tabular-shaped stopes, they recommended that photo-elastic methods be used and they illustrated the stress distribution around a slot in a plate subjected to vertical pressure. Denkhaus (1958) published a seminal paper with the title: 'The application of the mathematical theory of elasticity to problems of stress in hard rock at great depth.' This paper is rarely quoted by the rock engineering fraternity in modern times, but it is a key source illustrating the early adoption of elastic theory for analysis in the South African mining industry. Figure 11, for example, illustrates Denkhaus' proposal to use the principle of superposition and the analytical solutions for the stress around circular and elliptical openings to illustrate the elevated stress in the 'remnant' between the two openings.

Regarding who should be credited with first proposing elastic theory for use in the South African mining industry, Denkhaus, Hill, and Roux (1958) note that in 1952 the Central Mining - Rand Mines Group commissioned a research team from the CSIR to investigate the rock stress problem at depth. This initiative proved to be so successful that that in 1956 the Transvaal and Orange Free State Chamber of Mines agreed to assume sponsorship of the research programme. To oversee the work, a 'Rockburst and Strata Movement Research Committee' composed of members from the Chamber of Mines, the CSIR, and mining groups was established. A key task of the research team was to investigate if the stress around mining excavations can be determined by mathematical analysis. A major driver for the research team's proposal to use elastic theory was that laboratory compression tests on rock specimens from the Witwatersrand indicated that rock behaves essentially elastically up to the point of failure. Denkhaus (1958) referred to earlier papers from other countries that applied elastic theory to mining problems, such as Terzaghi and Richart (1952). Regarding the fracture zone, Denkhaus admitted that 'Obviously this fracture zone, which does not necessarily extend up to surface, cannot be regarded as a continuous elastic solid body to which the theory of elasticity

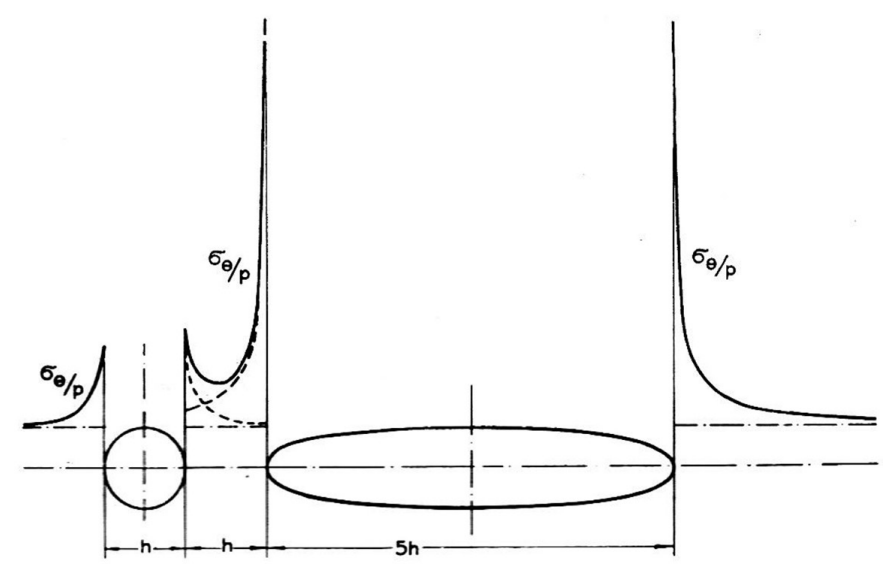

Figure 11-Stress distribution in the rock between a circular and elliptical opening subjected to a uniaxial vertical load (after Denkhaus, 1958) 


\section{A review of the role of underground measurements in the historical development}

can be applied. The stress in the solid rock surrounding the fracture zone, particularly the stress at the boundary of the fracture zone, can be determined by means of the theory of elasticity, however.' Interestingly, he also admitted that the effect of creep is beyond the scope of elastic theory, as he must have been aware of the time-dependent closure measurements that his colleague Leeman collected.

It is of interest to note that at the same time as these studies were carried out a number of breakthroughs were achieved in coal mine design. A significant early contribution was the publication of the paper by Hackett in 1959 in which a parallelsided panel geometry was suggested to be analogous to a crack in an elastic medium, with the important distinction that the opposing faces of the crack could interpenetrate one another in the same manner as the roof and floor of a mine excavation. Hackett used this model to explore the distribution of the stress state and displacements near a parallel-sided panel excavation. He found that predicted displacements were in good qualitative agreement with available field measurements. It is of great interest that Hackett acknowledges the contributions of $\mathrm{R}$. Hill for his technical support of the suggested approach. This pioneering work was followed by a series of ground-breaking papers by Berry $(1960,1964)$ and Berry and Sales $(1961$, 1964) which laid the theoretical foundation for the numerical technique now commonly referred to as the Displacement Discontinuity Method (DDM). Berry (1960) makes the following explicit acknowledgement: 'The author is grateful for much helpful discussion on various aspects of the problem to his colleagues, Mr. T.W. Sales, Dr. P. Hackett, Professor F.B. Hinsley and particularly to Professor $R$. Hill who was responsible for the fundamental idea of the excavation as a dislocation.' It is not commonly realized that the basic concept of representing a narrow tabular mine excavation as a 'crack' is apparently due to R. Hill, who is known more widely for his seminal text on plasticity theory (Hill, 1950). It is of interest as well that the time-dependent nature of ground movements near coal mine excavations was also recognized in the paper by Berry (1964), which includes a section on the representation of the host medium as a viscoelastic material.

The description of the tabular excavation model as a 'displacement discontinuity' is used several times by Berry $(1960,1964)$ and by Berry and Sales $(1961,1964)$. The same concept was introduced in the early foundational papers written by Salamon (1963, 1964a, 1964b, 1965) and was termed by him the 'Face Element Principle'. Salamon also introduced two further models to describe rock strata flexure in addition to the isotropic elastic and transverse isotropic elastic models. These novel alternatives include the so-called 'frictionless laminated model' comprising a quasi-continuum derived from the vertical response of a stack of contiguous, horizontal elastic plates and the "multimembrane model' in which bedded strata are approximated by a large number of horizontal membranes (which do not support bending moments) connected by a large number of vertical springs.

The displacement discontinuity technique was formulated in numerical computer codes in the late 1960s using then newly available mainframe computers. Early examples of these efforts were presented by Starfield and Fairhurst (1968) and by Plewman, Deist, and Ortlepp (1969). A description of the popular South African tabular mine design tool, known as MINSIM, which was developed at the Chamber of Mines of South Africa Research
Organisation (COMRO) was published by Deist, Georgiadis, and Moris (1972).

The displacement discontinuity method, however, only became recognized as an identifiable numerical technique analogous to the finite element method following the publication of papers by Crouch (1976) and the subsequent publication of the now iconic textbook by Crouch and Starfield in 1983. The technique is exhibited in this text in a much more general setting than as a specialized tool for tabular mine excavation analysis and has been used extensively for the analysis of geological fault mechanics, fracture mechanics and fracture growth, and notably for the analysis of fluid-driven hydraulic fracture propagation.

The adoption of the elastic concept was reinforced by another set of famous deformation measurements conducted early in the 1960s. Ryder and Officer (1964) measured the rock mass deformation in the hangingwall and footwall near the $K$ and L longwalls at ERPM from 1961 to 1963 (Figure 12). The 58 haulage in the hangingwall and the 68 haulage in the footwall provided access to regions remote from the stopes and away from the fracture zone (Figure 13).

Vertical displacements were measured in the haulages using accurate surveying techniques and a number of benchmark points spaced along the haulages. The measurement points were anchored 8 feet into the rock to avoid the influence of local fractured material. The results obtained for the 68 haulage are shown in Figure 14. The longwall mined over this footwall haulage and the upward movement of the haulage is shown. These results are compared to the displacement predicted by a 2D analytical elastic solution of an inclined slit (to represent the stope). The results for the 58 haulage are shown in Figure 15. As this haulage was in the hangingwall, the parts being undermined moved downwards. In both cases the agreement between the measured and theoretical displacements was good, in spite of the fact that a 2D analytical solution was used. These graphs are historically significant as the study was the first to compare theoretical elastic displacements in the rock mass with actual movements observed in the vicinity of a deep-level longwall (it was the first comparison between movements and elastic theory as confirmed by Ortlepp and Nicoll, 1964).

Based on this good fit, the authors concluded that the observed displacements in the rock mass remote from mining excavations are essentially in agreement with elastic theory. It was also found that the elastic constants determined from small specimens appear to be a good estimate of the properties of the rock mass underground. The values used in this study were a Young's modulus of $80 \mathrm{GPa}$ and a Poisson's ratio of 0.16 .

Ortlepp and Cook (1964) used a similar simplified 2D elastic solution to compare measurements close to a longwall at Harmony Gold Mine with elastic theory. Ortlepp and Nicoll (1964) extended the work of Ryder and Officer (1964) by using an electrical analogue to simulate the rock movements at Harmony Gold Mine and ERPM. This analogue could account for the complex geometry. This work confirmed the earlier simplified elastic analyses and validated the concept of elastic behaviour for the rocks in the South African gold mines. The updated fit for the 58 hangingwall haulage at ERPM is shown in Figure 16.

Based on this flurry of publications using elastic theory to predict far field rock mass movements, significant effort was dedicated in the years that followed to develop further techniques to simulate complex 3D layout geometries (e.g. Salamon, 1963, 1964a, 1964b). As this required a significant effort, it 


\section{A review of the role of underground measurements in the historical development}

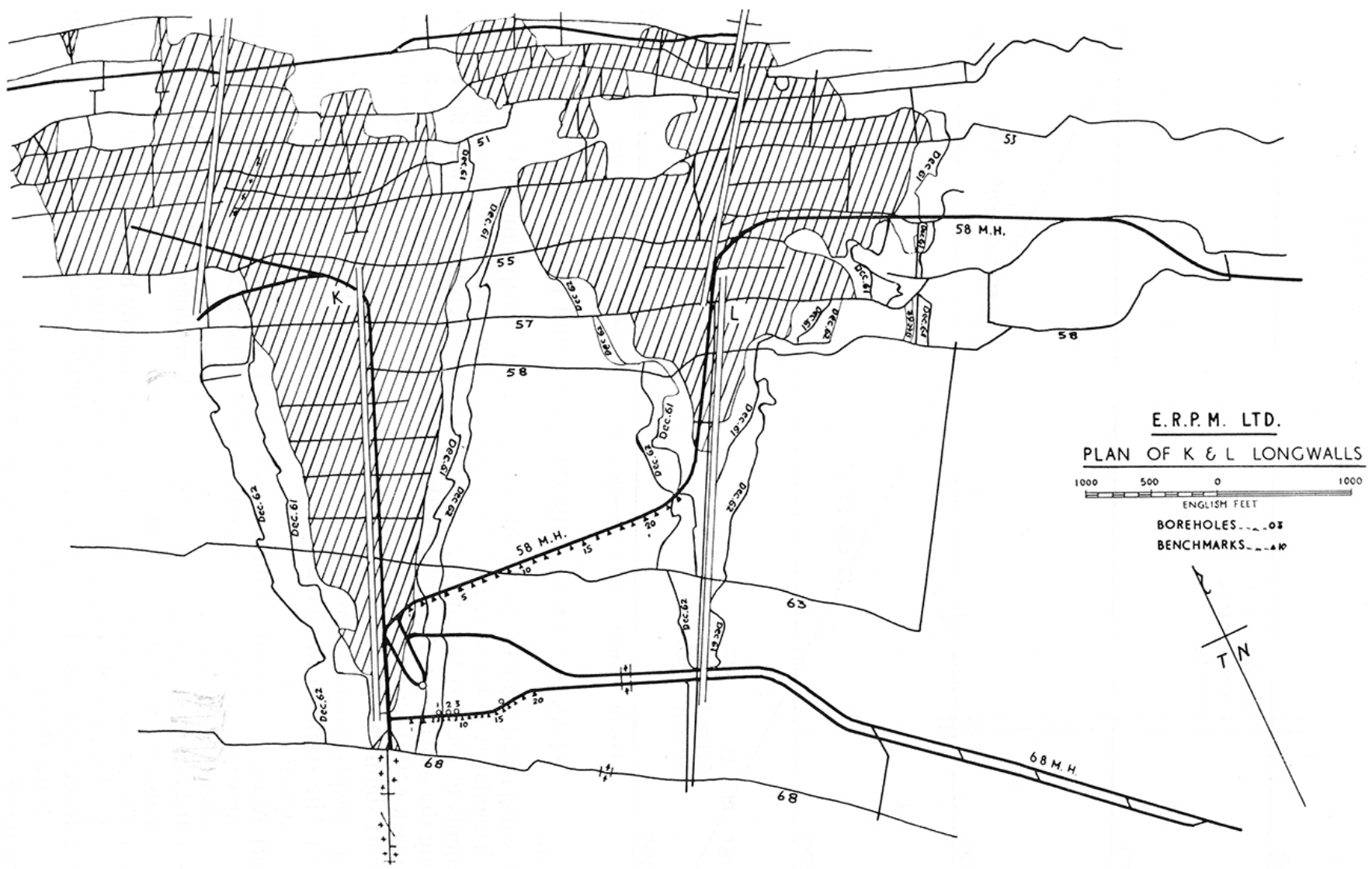

Figure 12-Mining geometry at the start of the deformation monitoring experiment at the $K$ and $L$ longwalls at ERPM (after Ryder and Officer, 1964)

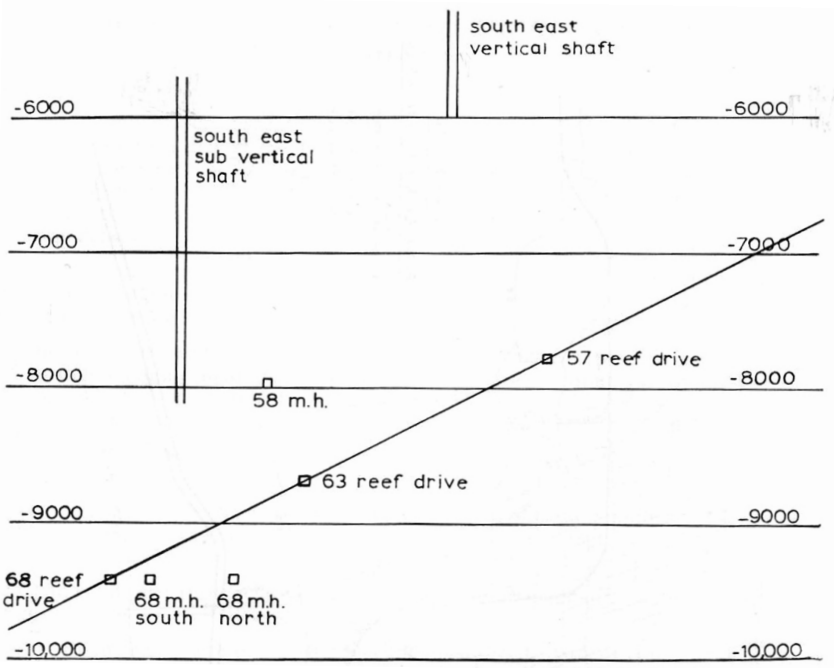

Figure 13-Section through the K longwall at ERPM showing the elevations of the 58 haulage and 68 haulage (after Ryder and Officer, 1964)

is hypothesised that the behaviour of the fracture zone and associated time-dependent behaviour recorded earlier by Leeman (1958) was not given the necessary attention.

\section{Early work on the time-dependent behaviour of the rock mass}

Roux and Denkhaus (1954) already hypothesised that the rock mass behaves in a time-dependent fashion, as rockbursts frequently occurred several hours after blasting when no changes in geometry occurred that could affect the stress field. They conducted creep tests on quartzite specimens and illustrated that time-dependent behaviour was observed for these specimens. Hodgson (1967) referred to the successful use of elastic theory to describe the far field rock mass behaviour and the design criteria proposed on the basis of this, but noted that 'The behaviour of the rock in the region between the elastic solid and the excavation is of the most immediate concern to mining practice but has been inadequately formulated.' He suggested that if continuous measurements of closure are recorded, an estimate can be made of the proportions of energy change associated with 


\section{A review of the role of underground measurements in the historical development}

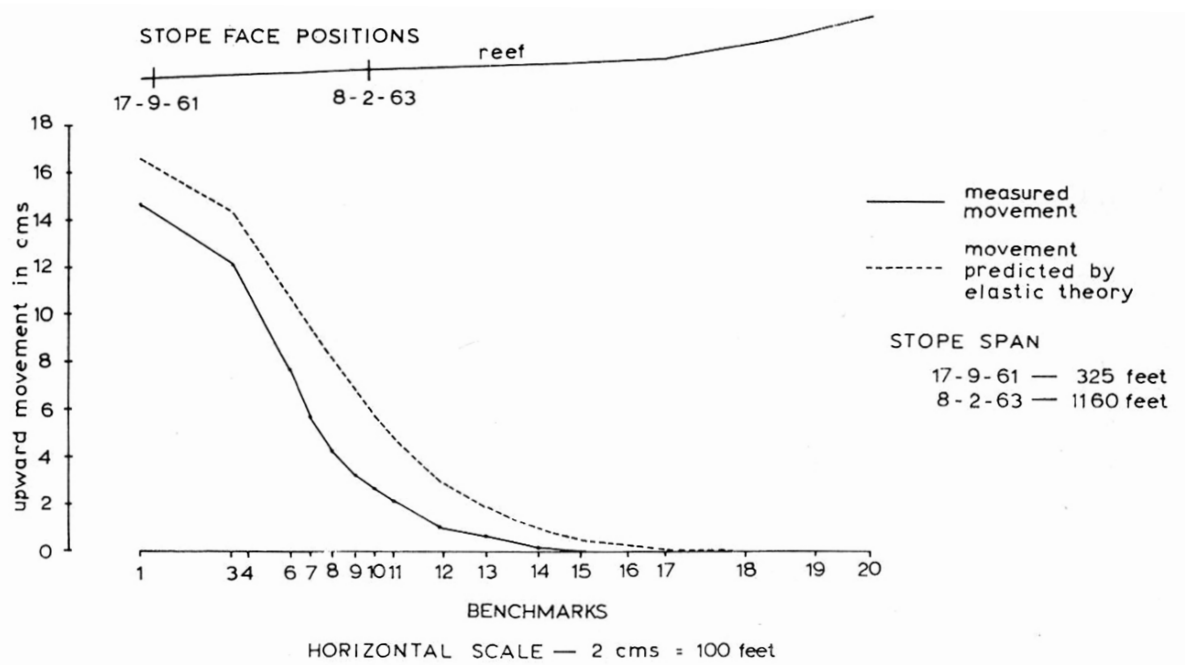

Figure 14-Comparison between the measured and theoretical 2D elastic displacement of the 68 footwall haulage at ERPM between 1961 and 1963 (after Ryder and Officer, 1964)

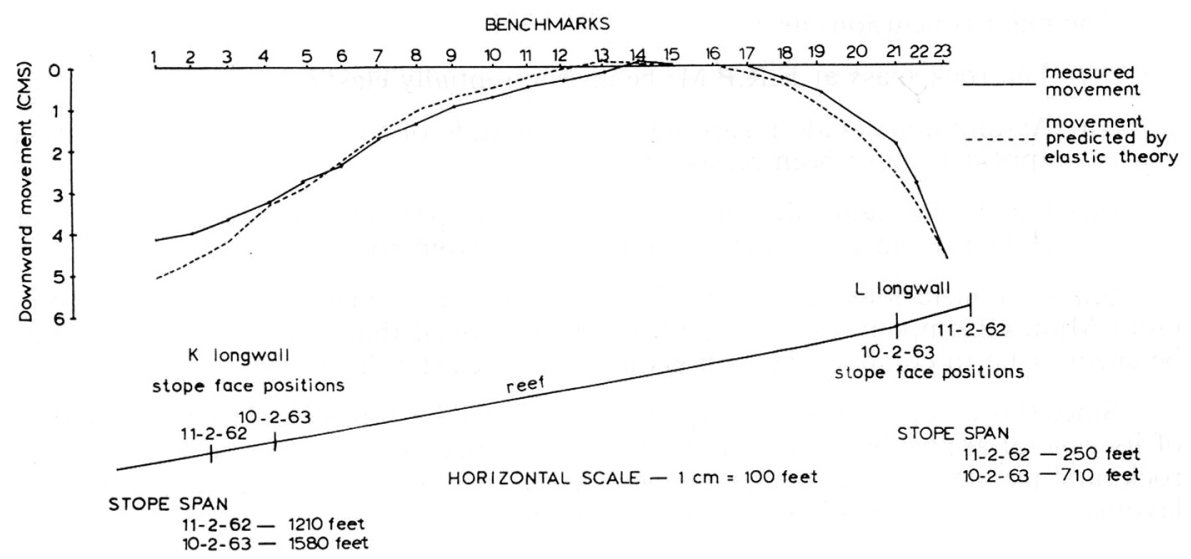

Figure 15-Comparison between the measured and theoretical 2D elastic displacement of the 58 hangingwall haulage at ERPM beween 1961 and 1963 (after Ryder and Officer, 1964)

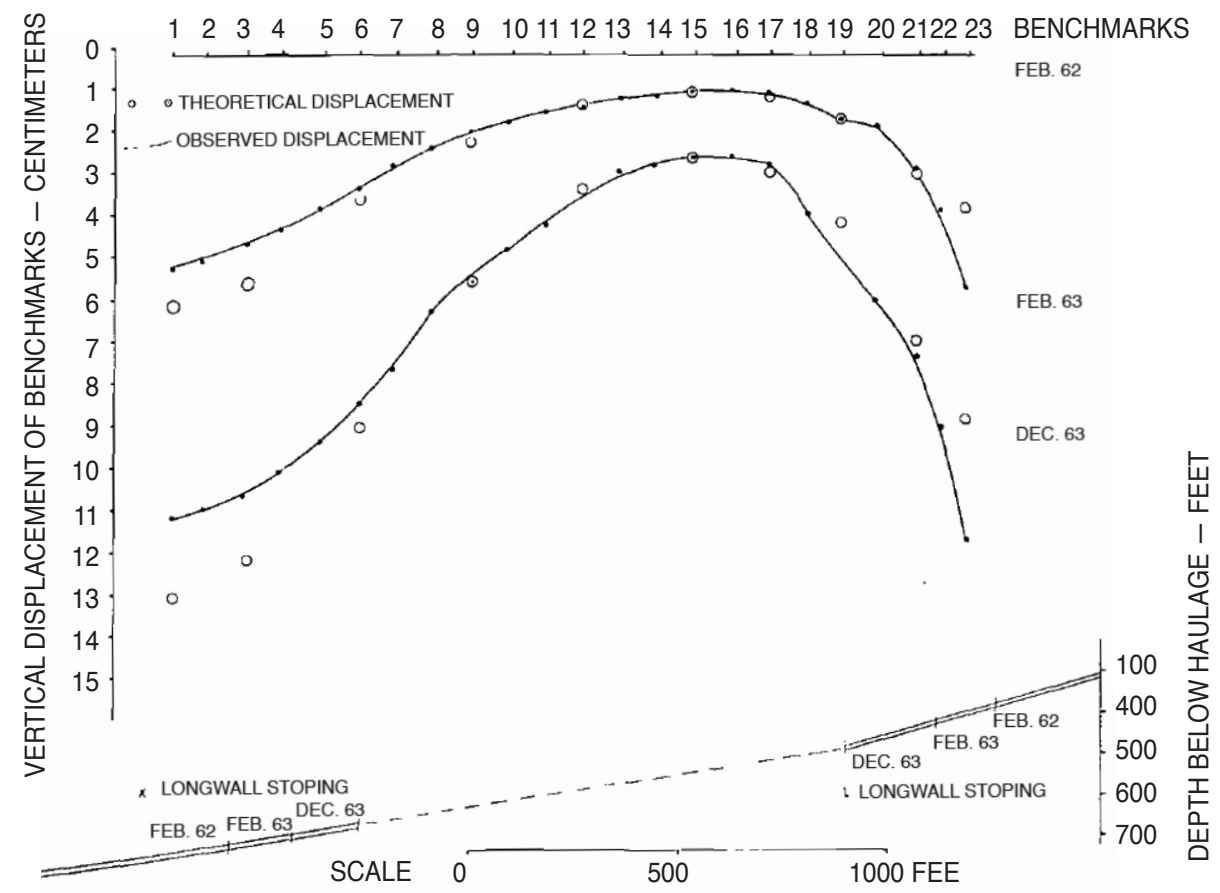

Figure 16-Comparison between the measured and theoretical 3D elastic simulation of the 58 hangingwall haulage at ERPM (after Ortlepp and Nicoll, 1964) 


\section{A review of the role of underground measurements in the historical development}

violent and non-violent energy release. Hodgson collected data in the $\mathrm{K}$ and $\mathrm{L}$ longwalls at ERPM. The convergence meter was a nickel-chrome wire anchored in a borehole at a depth of 50 feet in the hangingwall, which extended through the stope into the crosscut below, 50 feet into the footwall, and was tensioned by springs. The instrument is shown in Figure 17. An LVDT was used to record the displacement of the wire on a continuous basis.

Hodgson found that the long-term total convergence was in agreement with the elastic displacements from stope geometry changes, but there was a time-dependent component controlled by the behaviour of the failed rock near the face. He examined the energy balance proposed by Cook et al. (1966) and proposed that the time-dependent convergence has implications for mining cycles, rates of face advance, and stope support. He proposed a model - a migrating fracture zone to account for the observed closure behaviour (Figure 18). Based on this model, he suggested that the rockburst hazard will increase if too high a face advance rate is attempted.

Hodgson concluded by stating that 'The observations have shown that the most important property of the failed zone is time-dependent behaviour and that this behaviour is of direct concern to practical problems of designing support, face advance per blast and frequency of blasting so as to minimize the rockburst problem or, at least avoid aggravating it.'

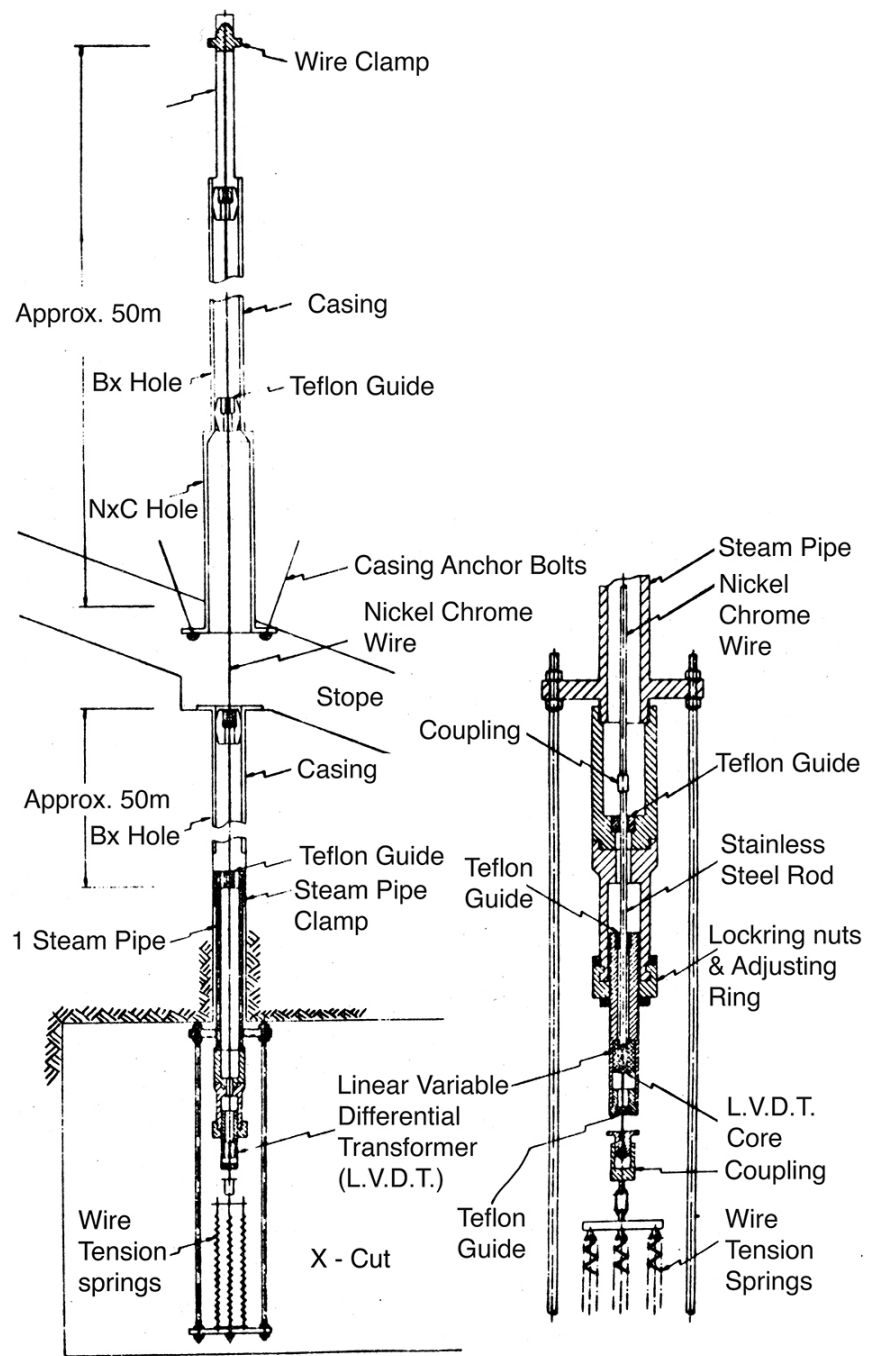

Figure 17-Convergence meter used by Hodgson (1967)
This was a profound statement, but unfortunately this important work was not considered again until the 1990s (Malan, 1999, 2002).

\section{In-situ tests on large rock specimens}

Although not related to closure measurements, this section is included to illustrate the elaborate underground measurements that were conducted on large coal specimens in the early 1970s. This is a useful illustration of what can be achieved with appropriate planning and the value that can be gained from these tests. It unfortunately also demonstrates that once concepts in rock engineering become entrenched, it is very difficult to displace them, even if good experimental results are obtained that indicate possible better solutions.

Cook, Hodgson, and Hojen (1971) describe the use of a 100 MN jacking system to test coal pillars underground. This was an important test of the empirical relationship (Equation [1]) proposed by Salamon and Munro (1967) and it is surprising that this paper by Cook is almost never quoted in the literature. A motivation for this study was that ever-larger coal pillars are required as the depth of mining increases (similar to the current problem faced by the platinum industry). One suggested solution was the use of barrier pillars and smaller yield pillars between these barriers. The complete load-deformation curves for the pillars were required. A system of jacks was developed to load pillars with a cross-section of $2 \mathrm{~m} \times 2 \mathrm{~m}$ in the underground workings. The jacks were installed in a horizontal slot along the central plane of symmetry of a pillar. A photograph available to the author of these kinds of experiments by the Chamber of Mines is shown in Figure 19. The work by Cook, Hodgson, and Hojen (1971) is shown in Figure 20. The agreement between these test results and the empirical equation developed by Salamon and Munro (1967) is shown in the figure.

Bieniawski and van Heerden (1975) gave an overview of large-scale in-situ tests done throughout the world. Bieniawski himself was involved with the testing of 66 large coal specimens in underground mines. Based on this work, Bieniawski proposed

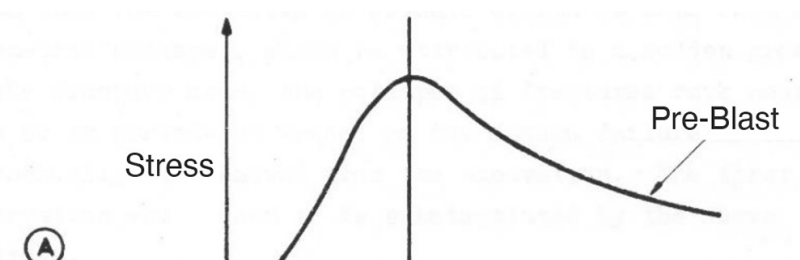

Elastic

Apparent size - - Blast advance

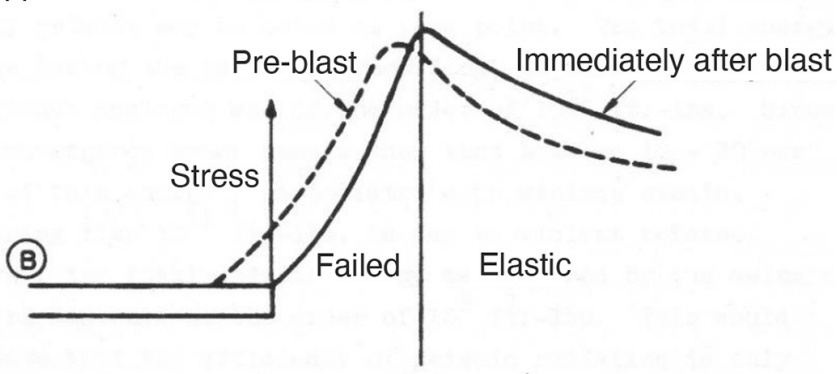

Figure 18-Migration of the fracture zone as proposed by Hodgson (1967). He suggested this migration occurs in a time-dependent fashion to account for the observed closure behaviour 


\section{A review of the role of underground measurements in the historical development}

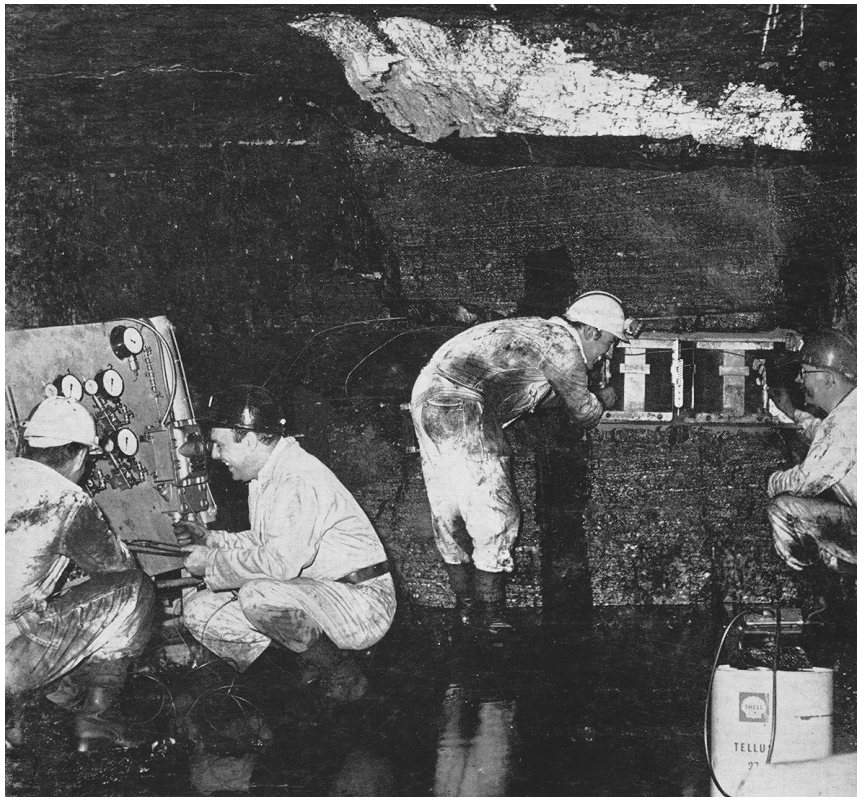

Figure 19-Loading of a coal pillar by jacks installed in a slot cut in the pillar that the linear formula given in Equation [3] is preferable for describing the strength of coal pillars (Figure 21).

In spite of the disagreement regarding the most appropriate empirical strength formula to use, the underground coal experiments further increased the confidence in coal pillar strength. In contrast, appropriate experimentation was never done on the platinum mines to verify the formulae used and the uncertainty regarding pillar strength remains to this day.

\section{Problems caused by the adoption of elastic theory}

As noted by Hoek (2006), in the book by Jaeger and Cook, Fundamentals of Rock Mechanics (1969), structural discontinuities are described on only approximately a dozen of the 500 pages of the book. This illustrated the dominance of elastic theory in the approach to rock mechanics associated with deep-level mining in the early years. By the 1980s, elastic theory was firmly entrenched in the design of layouts and the application of the associated ERR criterion was a key aspect of the strategy to control rockbursts (see, e.g. Heunis, 1980). As stated by Heunis: 'Irrespective of the method used, the effectiveness of reducing the energy released by mining depends strictly on the prevention of elastic closure and ride in the mined out area'. The focus on
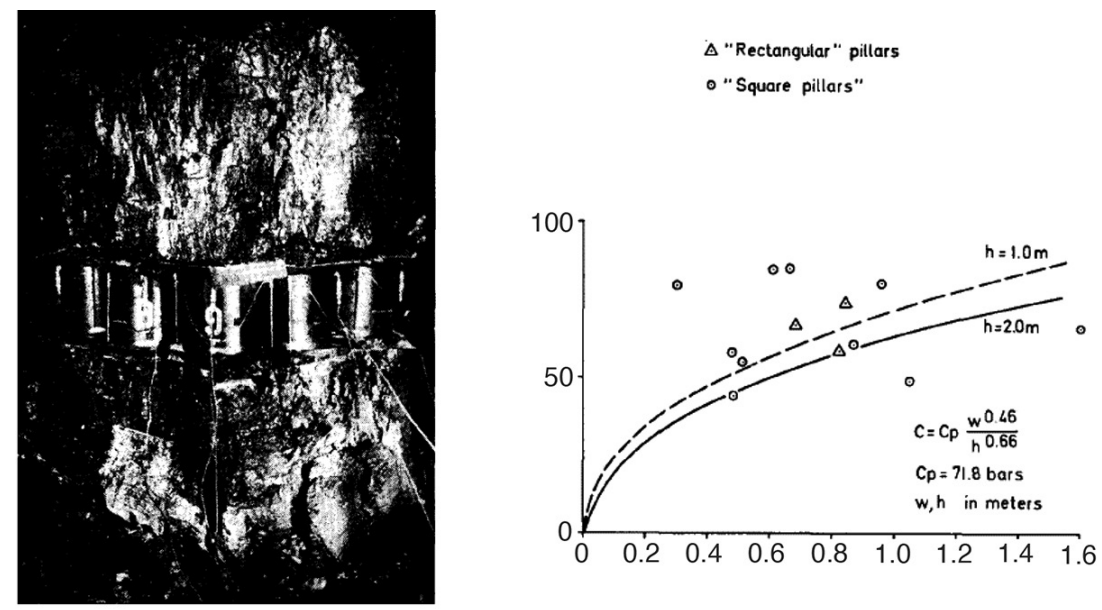

Figure 20-Experimental work conducted to test the in-situ strength of coal pillars (after Cook, Hodgson, and Hojen, 1971). The graph on the right illustrates the predicted strengths using the power law strength formula and the test results of all the pillars tested

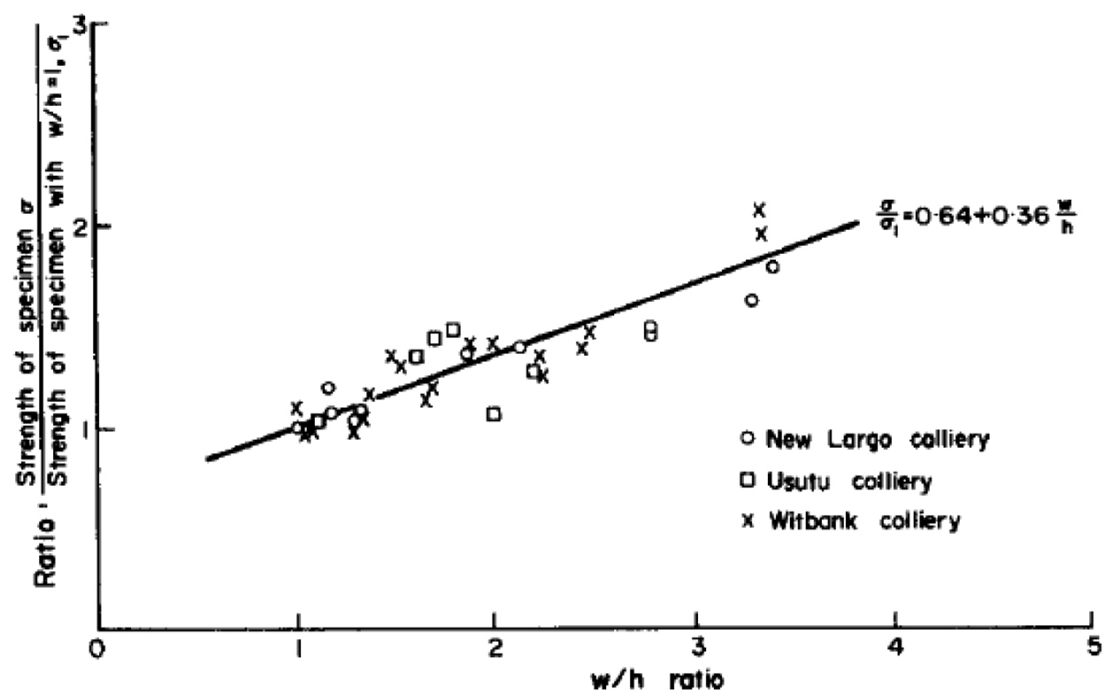

Figure 21-Results from the large-scale tests conducted underground, and a fit using Equation [3] (after Bieniawski and van Heerden, 1975) 


\section{A review of the role of underground measurements in the historical development}

elastic closure resulted in difficulties when researchers attempted to analyse detailed measurements of stope closure, as illustrated below.

Walsh et al. (1977) conducted closure measurements at West Driefontein Gold Mine. Data from four closure stations at a distance of less than $15 \mathrm{~m}$ from the face showed that convergence and ride are significantly larger than predicted by elastic theory. They suggested that 'Slip on cracks in the hangingwall and footwall apparently controls deformation in this region.' Gurtunca and Adams (1991) published a paper with a proposal to determine the in-situ modulus of the rock mass by using backfill measurements. They measured convergence in stopes supported by backfill and found that the closure is significantly higher than that predicted by elastic theory when using the MINSIMD modelling package and a Young's modulus of $70 \mathrm{GPa}$ (Figure 22). They recommended a reduction in the Young's modulus to more accurately simulate the closure, and values between $40 \mathrm{GPa}$ and $70 \mathrm{GPa}$ were deemed more appropriate. They mentioned that it is difficult to separate the magnitudes of inelastic closure from the elastic convergence, but recognized that the inelastic behaviour of the rock mass caused by the fracture zone around these stopes is responsible for the unexpectedly large closure measured in the backfill. They proposed that 'The use of an in situ modulus provides an effective interim solution until a new computer model that allows for joints, different layers, and inelastic closures becomes generally available.'

Stacey (1991), in his response to the Gurtunca and Adams (1991) paper, felt that this interim solution should not be used as a downgraded elastic modulus is no more correct than any other modulus that has been used. What is required is greater engineering understanding and interpretation by rock engineers when using the existing tools.

These controversies arose as a suitable model to simulate the inelastic stope closure and the prominent time-dependent stope closure, recorded as long ago as 1935, was never developed. Elastic theory and numerical modelling techniques made the simulation of stress and displacement for irregular geometries on a stope-wide scale possible. This was such a huge step forward that ignoring the effect of the fracture zone was deemed acceptable.

\section{Recent measurements of time-dependent rock deformation}

The early time-dependent closure results from Leeman (1958) and hypotheses of mining rate behaviour by Hodgson (1967) were further investigated by Malan, Napier, and Janse van Rensburg (2007). Malan conducted extensive measurements of continuous closure in a number of gold mines and profiles similar to that illustrated in Figure 9 were obtained. It was also discovered for the first time that the closure behaviour of crush pillar layouts in the intermediate depth platinum mines also contain a significant time-dependent component (Figure 23). The closure data was found to be a wonderful diagnostic for rock mass response.

Malan, Napier, and Janse van Rensburg (2007) found that the closure measurements contained a significant timedependent component in spite of the brittle nature of the rock. Time-dependent rates as high as $1 \mathrm{~mm} / \mathrm{h}$ were measured in extreme cases. The time-dependent closure component appears to be ubiquitous in the gold mines and intermediate depth platinum mines and is even observed in very brittle environments such as Ventersdorp Contact Reef stopes with a Ventersdorp lava hangingwall. Various approaches to simulate the timedependent closure have been investigated since this work was initiated. Plane strain analytical solutions for the convergence of stopes where the rock behaves as a Burgers viscoelastic material in distortion were derived (Malan, 2002). These models gave a reasonable fit to data recorded underground. Although viscoelastic theory therefore appears to be able to simulate timedependent closure behaviour, there are subtle problems with the use of this theory as it cannot simulate the failure processes in the rock and care should be exercised when attempting to use these models. To overcome these problems, continuum and discontinuum elasto-viscoplastic models have been developed. Discontinuum models have the advantage of being able to simulate the creep behaviour of prominent discontinuities. The development of these models has provided useful insights into rock mass deformation and has enabled the simulation of parameters such as rate of mining to be conducted for the first time.

By recording the time-dependent closure behaviour, a number of practical applications for the mining industry became available. Among these are the delineation of geotechnical areas using closure data, use of the data as a hazard indicator, and to give warning of large collapses in the platinum mines (Figure 24), identification of areas in need of preconditioning in the gold mines, measurement of the effectiveness of preconditioning, and improved data for support design to include the effect of mining rate. Additional detail is given in Malan, Napier, and Janse van Rensburg (2007).

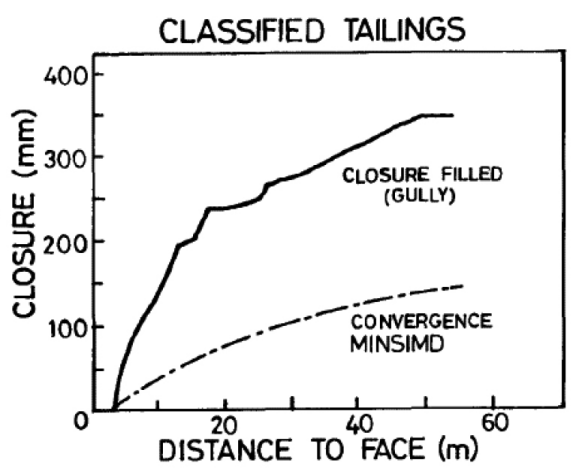

Figure 22-Difference between closure measured in a backfilled stope and elastic modelling (MINSIMD) (after Gurtunca and Adams, 1991)

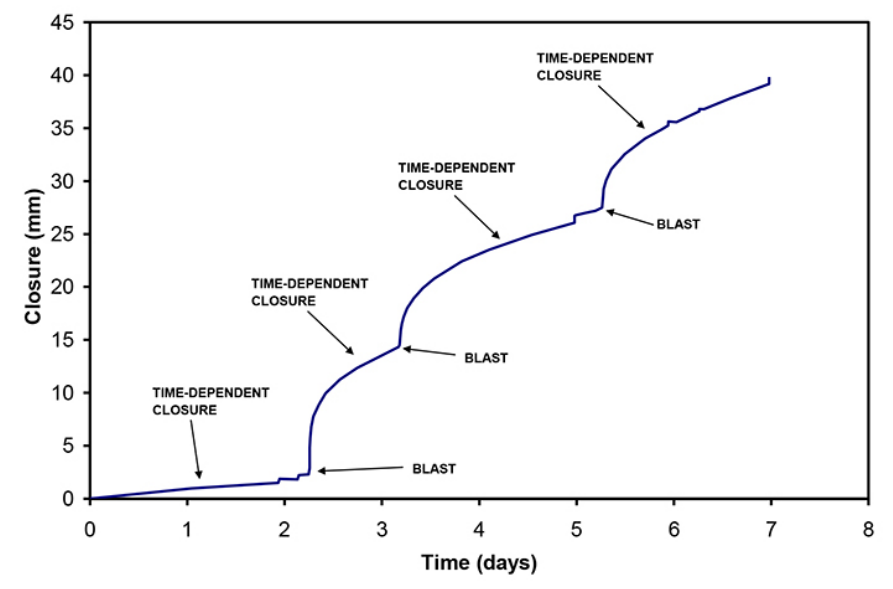

Figure 23-Typical continuous closure behaviour in a deep Merensky Reef stope (after Malan, Napier, and Janse van Rensburg, 2007). 


\section{A review of the role of underground measurements in the historical development}

Malan and Napier (2018) investigated the use of a timedependent limit equilibrium model to simulate the historical timedependent closure profiles collected in the South African mining industry. Earlier work indicated that a viscoelastic creep model is not suitable for replicating the spatial behaviour of the closure recorded underground. The time-dependent limit equilibrium model appears to be a useful alternative as it can explicitly simulate the on-reef time-dependent failure of the reef. A key finding in this paper is that the model gives a better qualitative agreement with the underground closure measurements (Figure 25). For both the model and actual data, the rate of time-dependent closure decreases into the back area. Explicit simulation of the fracture zone in the face appears to be a better approach to simulating the time-dependent behaviour in deep hard-rock stopes. The calibration of the limit equilibrium model nevertheless remains a difficult problem. Using this model, Napier and Malan (2018) simulated the effect of mining rate. Figure 26 illustrates the effect of different mining rates and sequences for two hypothetical adjacent $25 \mathrm{~m}$ panels. The total area mined is equal to $1500 \mathrm{~m}^{2}$. For the fast mining, both panels are advanced every day with an increment length of $1 \mathrm{~m}$; for the slow rate, the mining cycles between the panels, and for the $0.5 \mathrm{~m}$ increment, both panels are mined together. The effect of mining rate on energy released is shown in the figure and it appears that the model is at least qualitatively able to simulate what has been suspected about mining rates in industry for a long time.

It has been recognized for many years that time-dependent deformations are often a prominent feature of the observed behaviour of coal mine workings. This plays an important role in determining the long-term stability of pillar layouts. The early pillar design formula established by Salamon and Munro (1967), and subsequently extended by Madden (1991) to include pillars having a large width to height ratio, did not contain any explicit incorporation of time-dependent strength decay. Subsequent work by Salamon, Ozbay, and Madden (1998) included a proposed pillar edge scaling model to describe the long-term stability of pillars. A detailed critique of the merits of the squat pillar formula has been published recently by Mathey and van der Merwe (2016). A number of empirical relationships have been proposed by van der Merwe (2012, 2016a, 2016b) to enable

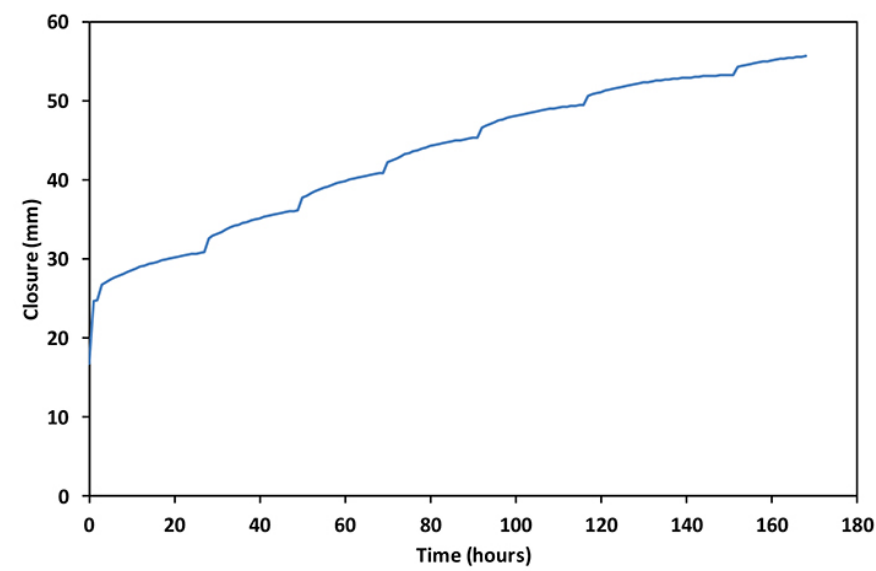

Figure 25-Simulated time-dependent closure curve for a number of mining steps (after Malan and Napier, 2018)

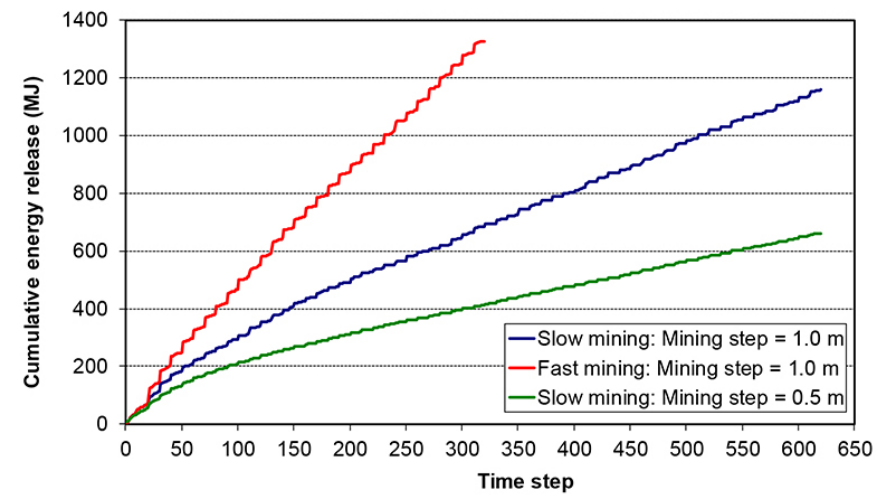

Figure 26-Accelerated closure recorded before a massive collapse in a UG2 panel (after Malan, Napier, and Janse van Rensburg, 2007)

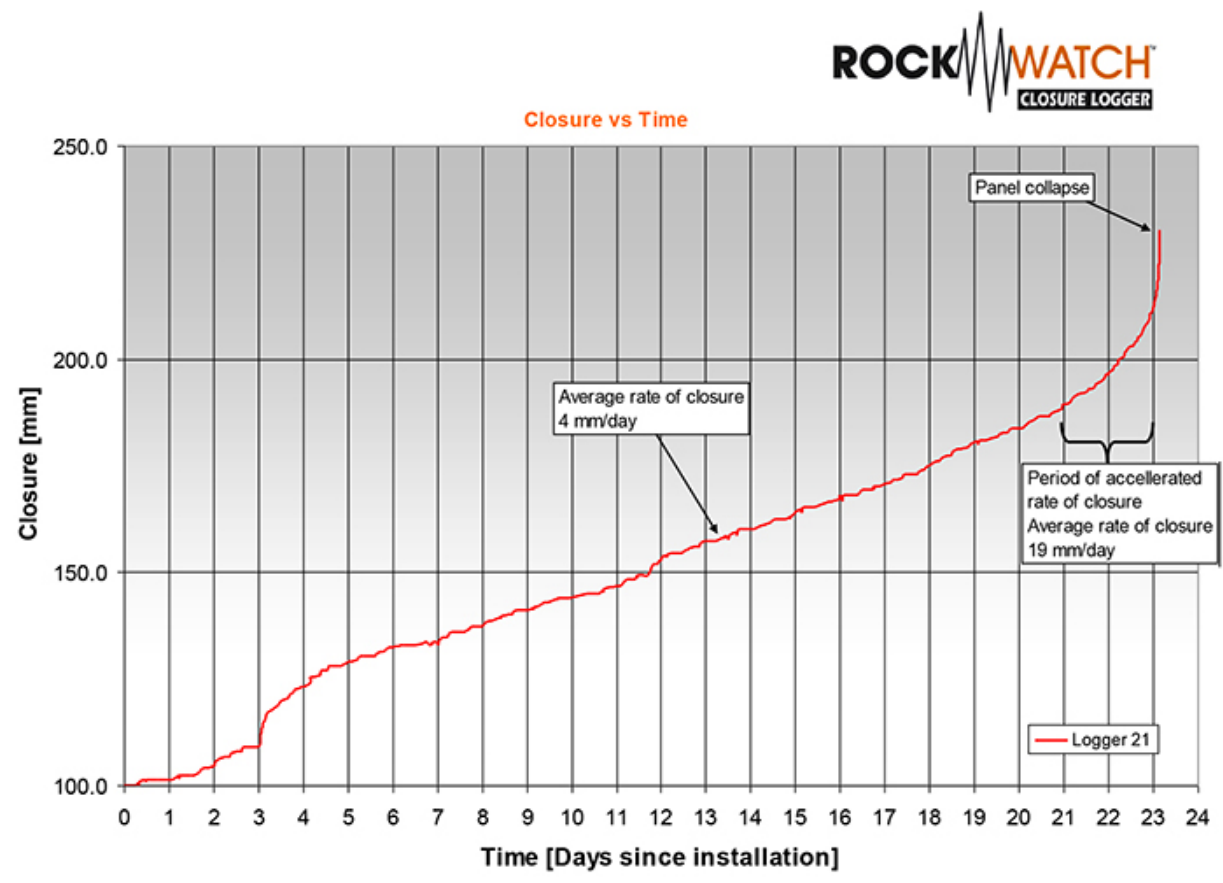

Figure 24-Accelerated closure recorded before a massive collapse in a UG2 panel (after Malan, Napier, and Janse van Rensburg, 2007) 


\section{A review of the role of underground measurements in the historical development}

firmer design predictions of the strength properties for the life of coal pillars. This is particularly important in coal mine operations where the workings may be at a shallow depth and the long-term collapse of the original pillar system can lead to severe surface infrastructure damage up to several decades after the cessation of mining activity. It would seem that in this case there is a critical need for numerical modelling design tools to incorporate timedependent pillar scaling and damage mechanisms.

\section{Conclusions}

This paper has described some interesting aspects associated with historical underground measurements in South African gold and coal mines. Elastic theory was introduced in the 1950s and deformation measurements were used to confirm the applicability of elastic theory to simulate the rock mass behaviour in the 1960s. Although the prominent time-dependent component of stope closure was measured as early as 1934, it was conveniently ignored owing to the benefit of adopting simple elastic theory. Ignoring the time-dependent response of the rock for many decades resulted in important aspects such as the effect of mining rate, the effect of advance per blast, and the need for enhanced design criteria being neglected in the gold mines. Only recently was work started to address this gap in knowledge. Continuous closure measurements may possibly be a good diagnostic measure of the stress acting on remnants. This hypothesis needs to be carefully tested. In the platinum mines, time-dependent closure data is a good indication of effective pillar crushing. Absence of crushing may lead to pillar bursting and closure measurements may possibly be used to identify these areas. This also needs to be researched in more detail. A key lesson to be learnt from history is that monitoring data may reveal unexpected rock mass behaviour that does not fit with preconceived ideas. Any anomalous behaviour must not be ignored as it may contain diagnostic information that will assist with the development of safe mining practices and stable excavations.

The in-situ measurements of large coal specimens in the 1960s and 1970s indicated that a linear formula may be a better approximation of coal pillar strengths. This alternative formulation was never adopted, however, as the power law strength formula was already deeply entrenched in the industry at that stage. In spite of these apparent failures, a key lesson learnt from these historical measurements is that major advances in the field of rock mechanics will not be possible without careful monitoring of the rock mass behaviour in experimental sites. Appropriate strength formulae for pillars in the Bushveld Complex and enhanced design criteria for the gold mines can only be developed using extensive underground monitoring programmes.

\section{Acknowledgements}

This work forms part of research conducted in the Harmony Gold Chair of Rock Engineering and the authors would like to thank Harmony Gold for their kind support.

\section{References}

Altson, B.T. 1933. Remarks on sand-filling. Papers of the Association of Mine Managers of South Africa, 1931-1936. pp. 429-432.

BarczA, M. and von Willich, G.P.R. 1958. Strata movement measurements at Harmony Gold Mine. Papers of the Association of Mine Managers of South Africa, 1958-1959. pp. 447-464.
BERRY, D.S. 1960. An elastic treatment of ground movement due to mining I. Isotropic ground. Journal of the Mechanics and Physics of Solids, vol. 8. pp. 280-292.

BERRY, D.S. and SAlEs, T.W. 1961. An elastic treatment of ground movement due to mining II. Transversely isotropic ground. Journal of the Mechanics and Physics of Solids, vol. 9, pp. 52-62.

BERRY, D.S. and SALES, T.W. 1964. An elastic treatment of ground movement due to mining III. Three dimensional problem, transversely isotropic ground. Journal of the Mechanics and Physics of Solids, vol. 9. pp. 73-8352-62.

BERRY, D.S. 1964. The ground considered as a transversely isotropic material. International Journal of Rock Mechanics and Mining Sciences. vol. 1. pp. 159-167.

BIENIAWSKI, Z.T. and van HEERDEN, W.L. 1975. The significance of in situ tests on large rock specimens. International Journal of Rock Mechanics and Mining Sciences and Geomechanical Abstracts, vol. 12. pp. 101-113.

BiENIAWSKI, Z.T. 1992. A method revisited: coal pillar strength formula based on field investigations. Proceedings of the Workshop on Coal Pillar Mechanics and Design. IC 9315. US Bureau of Mines.

Соoк, N.G.W., Hoek, E., Pretorius, J.P.G., Ortlepp, W.D., and Salamon, M.D.G. 1966. Rock mechanics applied to the study of rockbursts. Journal of the South African Institute of Mining and Metallurgy, vol. 66. pp. 435-528.

Соoк, N G.W., Hodgson, K., and Hojem J.P.M. 1971. A 100-MN jacking system for testing coal pillars underground. Journal of the South African Institute of Mining and Metallurgy, vol. 71. pp. 215-224.

CSIR. 1958. Second report on strata movement - Analyses of the results of strata movement measurements at Harmony goldmine during the year 1957. National Mechanical Engineering Research Institute, CSIR, Pretoria.

CRouch, S.L. 1976. Solution of plane elasticity problems by the displacement discontinuity method. International Journal for Numerical Methods in Engineering, vol. 10. pp. 301-343.

Crouch, S.L. and Starfield, A.M. 1983. Boundary Element Methods in Solid Mechanics. George Allen \& Unwin, London.

Deist, F.H., Georgiadis, E., and MoRis, J.P.E. 1972. Computer applications in rock mechanics. Journal of the South African Institute of Mining and Metallurgy, vol. 72. pp. 265-272.

Denkhaus, H.G. 1958. The application of the mathematical theory of elasticity to problems of stress in hard rock at great depth. Papers of the Association of Mine Managers of South Africa, 1958-1959. pp. 271-310.

Denkhaus, H.G., Hill, F.G., and Roux, A.J.A. 1958. A review of recent research into rockbursts and strata movement in deep-level mining in South Africa. Papers of the Association of Mine Managers of South Africa, 1958-1959. pp. 245-269.

DURRHEIM R.J. 2010/ Mitigating the risk of rockbursts in the deep hard rock mines of South Africa: 100 years of research. Extracting the Science: A Century of Mining Research. Society for Mining, Metallurgy, and Exploration, Inc., Phoenix, Arizona. pp. 156-171.

Gurtunca, R.E. and Adams D.J. 1991. Determination of the in situ modulus of the rockmass by the use of backfill measurements. Journal of the South African Institute of Mining and Metallurgy, vol. 91, no. 3. pp. 81-88.

HACKETT, P. 1959. An elastic analysis of rock movements caused by mining. Transactions of the Institution of Mining Engineering, vol. 118. pp. 421-435.

Hedley, D.G.F. and Grant, F. 1972. Stope-and-pillar design for Elliot Lake Uranium Mines. Bulletin of the Canadian Institute of Mining and Metallurgy, vol. 65. pp. 37-44.

Heunis, R. 1980. The development of rock-burst control strategies for South African gold mines. Journal of the South African Institute of Mining and Metallurgy, vol. 80. pp 139-150. 


\section{A review of the role of underground measurements in the historical development}

HILL, R. 1950. The Mathematical Theory of Plasticity. Oxford University Press, Oxford.

Hodgson, K. 1967. Report on the behaviour of the failed zone ahead of a face, as indicated by continuous seismic and convergence measurements. Research Report no. 31/67. Transvaal and Orange Free State Chamber of Mines Research Organisation. April 1967.

Новк, E. 2006. Practical Rock Engineering. https://www.rocscience.com/learning/ hoeks-corner/course-notes-books

JAEGER, J.C. and СоoK, N.G.W. 1969. Fundamentals of Rock Mechanics. Chapman and Hall, London.

Jooste, Y. and MaLan, D.F. 2020. The need for improved layout design criteria for deep tabular stopes. Journal of the Southern African Institute of Mining and Metallurgy, vol. 120, no. 1. pp 23-32.

LeEmAn, E.R. 1958. Some measurements of closure and ride in a stope of the East Rand Proprietary Mines. Papers of the Association of Mine Managers of South Africa, 1958-1959. pp. 385-404.

Madden, B.J. 1991. A re-assessment of coal pillar design. Journal of the South African Institute of Mining and Metallurgy, vol. 91. pp. 27-37.

MaLAN, D.F. 1999. Time-dependent behaviour of deep level tabular excavations in hard rock. Rock Mechanics and Rock Engineering, vol. 32, no. 2. pp. 123-155.

MaLAN, D.F. 2003. Manuel Rocha Medal Recipient: Simulating the time-dependent behaviour of excavations in hard rock. Rock Mechanics and Rock Engineering, vol. 35 , no. 4 .

MALAn, D.F. and NAPIER, J.A.L. 2011. The design of stable pillars in the Bushveld mines: A problem solved? Journal of the Southern African Institute of Mining and Metallurgy, vol. 111. pp 821-836.

MALAN, D.F. and NAPIER, J.A.L. 2018. Reassessing continuous stope closure data using a limit equilibrium displacement discontinuity model. Journal of the Southern African Institute of Mining and Metallurgy, vol. 118, no. 3. pp. 227-234.

Malan, D.F. Napier, J.A.L, and Janse van Rensburg, A.L. 2007. Stope deformation measurements as a diagnostic measure of rock behaviour: A decade of research. Journal of the Southern African Institute of Mining and Metallurgy, vol. 107, no. 11. pp. 743-765.

Mathey, M. and van der Merwe, J.N. 2016. Critique of the South African squat coal pillar strength formula. Journal of the Southern African Institute of Mining and Metallurgy, vol. 116, no. 3. pp. 291-299.

MickEL, R.E. 1935. Pressure bursts. Papers of the Association of Mine Managers of South Africa, 1931-1936. pp. 394-428.

NAPIER, J.A.L. and MALAN D.F. 2018. Simulation of tabular mine face advance rates using a simplified fracture zone model. International Journal of Rock Mechanics and Mining Sciences, vol. 109. pp. 105-114.

ORTLEPp, W.D . and Соoк, N.G.W. 1964. The measurement and analysis of the deformation around deep, hard-rock excavations. Proceedings of the International Conference on Strata Mechanics, Columbia University, New York, May 1964. Columbia University.

ORTLEPP, W.D. and NicolL, A. 1964. The elastic analysis of observed strata movement by means of an electrical analogue. Journal of the South African Institute of Mining and Metallurg, November 1964. pp. 214-235.

Roux, A.J.A. and Denkhaus, H.G. 1954. An investigation into the problem of rockbursts. An operational research project: Part II: An analysis of the problem of rockbursts in deep-level mining. Journal of the Chemical, Metallurgical and Mining Society of South Africa, vol. 55. pp. 103-124.

Plewman, R.P., Deist, F.H., and OrtLePp, W.D. 1969. The development and application of a digital computer method for the solution of strata control problems. Journal of the South African Institute of Mining and Metallurgy, vol. 70. pp. 33-44.

Ryder, J.A. and Jager, A.J. 2002. Rock Mechanics for Tabular Hard Rock Mines. Safety in Mines Research Advisory Committee, Johannesburg.
Ryder, J.A. and OfFICER, N.C. 1964. An elastic analysis of strata movement observed in the vicinity of inclined excavations. Journal of the South African Institute of Mining and Metalluryg, vol. 64, no. 6. pp. 219-244.

Ryder, J.A., WATSON, B.P., and KATAKA, M. 2005. PlatMine 1.2: Estimation of UG2 and Merensky Reef pillar strengths through back-analyses. PlatMine report, March 2005. Miningtek Division of CSIR, Johannesburg.

Salamon, M.D.G. 1963. Elastic analysis of displacements and stresses induced by the mining of seam or reef deposits - Part I: Fundamental principles and basic solutions as derived from idealised models. Journal of the South African Institute of Mining and Metallurgy, vol. 63. pp. 128-149.

Salamon, M.D.G. 1964a. Elastic analysis of displacements and stresses induced by the mining of seam or reef deposits - Part II: Practical methods of determining displacement, strain and stress components from a given mining geometry. Journal of the South African Institute of Mining and Metallurgy, vol. 64, no. . pp. 197-218.

Salamon, M.D.G. 1964b. Elastic analysis of displacements and stresses induced by the mining of seam or reef deposits - Part III: An application of the elastic theory: Protection of surface installations by underground pillars. Journal of the South African Institute of Mining and Metallurgy, vol. 64. pp. 468-500.

SALAmon, M.D.G. 1965. Elastic analysis of displacements and stresses induced by the mining of seam or reef deposits - Part IV: Inclined reef. Journal of the South African Institute of Mining and Metallurgy, vol. 65. pp. 319-338.

Salamon, M.D.G. and Munro, A.H. 1967. A study of the strength of coal pillars. Journal of the South African Institute of Mining and Metallurgy, vol. 68. pp 56-67.

Salamon, M.D.G., Ozbay, M.U., and Madden, B.J. 1998. Life and design of bord-andpillar workings affected by pillar scaling. Journal of the South African Institute of Mining and Metallurg, vol. 98. pp. 135-145.

Stacey, T.R. 1991. Written contribution on the paper by Gurtunca, R.E. and Adams, D.J. 1991. Determination of the in situ modulus of the rockmass by the use of backfill measurements. Journal of the South African Institute of Mining and Metallurgy, vol. 91, no. 8. pp. 286-288.

Starfield, A.M. and Fairhurst, C. 1968. How high-speed computers advance design of practical mine pillar systems. Engineering and Mining Journal, vol. 169. pp. 78-84.

SzwEDzicki, T. 1989. Geotechnical assessment deficiencies in underground mining. Mining Science and Technology, vol. 9. pp. 23-37.

TERzAGHI, K. and RicharT, F.E. 1952. Stresses in rock about cavities. Geotechnique, vol. 3. pp. 57-90.

Van der Merwe, J.N. 2012. Rock engineering method to pre-evaluate old, small coal pillars for secondary mining. Journal of the Southern African Institute of Mining and Metallurgy, vol. 111, no. 1. pp. 1-6.

VAN DER MERWE, J.N. 2016a. Review of coal pillar lifespan prediction for the Witbank and Highveld coal seams. Journal of the Southern African Institute of Mining and Metallurgy, vol. 116, no. 11. pp. 1083-1090.

VAN DER MERWE, J.N. 2016b. A three-tier method of stability evaluation for coal mines in the Witbank and Highveld coalfields. Journal of the Southern African Institute of Mining and Metallurgy, vol. 116, no. 12. pp. 1189-1194.

VAN DER MERWE, J.N. 2019. Coal pillar strength analysis based on size at the time of failure. Journal of the Southern African Institute of Mining and Metallurgy, vol. 119, no. 7. pp. 681-692.

Walsh, J.B., Leyde, E.E., White A.J.A., and CARRAgher B.L. 1977. Stope closure studies at West Driefontein Gold Mine. International Journal of Rock Mechanics and Mining Sciences and Geomechanical Abstracts, vol. 14. pp. 277-281.

Watson, B.P., Ryder, J.A., Kataka M.O., KujJPers, J.S., and Leteane F.P. 2008. Merensky pillar strength formulae based on back-analysis of pillar failures at Impala Platinum. Journal of the Southern African Institute of Mining and Metallurgy, vol. 108 , no. . pp. 449-61. 